Louisiana State University

LSU Digital Commons

8-9-2016

\title{
Copper(II) Ions Increase Plasminogen Activator Inhibitor Type 1 Dynamics in Key Structural Regions That Govern Stability
}

\author{
Joel C. Bucci \\ The University of Tennessee, Knoxville \\ Morten Beck Trelle \\ Syddansk Universitet \\ Carlee S. Mcclintock \\ The University of Tennessee, Knoxville \\ Tihami Qureshi \\ The University of Tennessee, Knoxville \\ Thomas J.D. Jørgensen \\ Syddansk Universitet
}

See next page for additional authors

Follow this and additional works at: https://digitalcommons.Isu.edu/biosci_pubs

\begin{abstract}
Recommended Citation
Bucci, J., Trelle, M., Mcclintock, C., Qureshi, T., Jørgensen, T., \& Peterson, C. (2016). Copper(II) Ions Increase Plasminogen Activator Inhibitor Type 1 Dynamics in Key Structural Regions That Govern Stability. Biochemistry, 55 (31), 4386-4398. https://doi.org/10.1021/acs.biochem.6b00256
\end{abstract}

This Article is brought to you for free and open access by the Department of Biological Sciences at LSU Digital Commons. It has been accepted for inclusion in Faculty Publications by an authorized administrator of LSU Digital Commons. For more information, please contact ir@lsu.edu. 


\section{Authors}

Joel C. Bucci, Morten Beck Trelle, Carlee S. Mcclintock, Tihami Qureshi, Thomas J.D. Jørgensen, and Cynthia B. Peterson 


\title{
Copper(II) lons Increase Plasminogen Activator Inhibitor Type 1 Dynamics in Key Structural Regions That Govern Stability
}

\author{
Joel C. Bucci, ${ }^{\dagger, \S}$ Morten Beck Trelle, ${ }^{\dagger}$ Carlee S. McClintock, ${ }^{\dagger}$ Tihami Qureshi, ${ }^{\dagger}$ Thomas J. D. Jørgensen, ${ }^{\dagger}$ \\ and Cynthia B. Peterson* $*, \dagger, \S$

\begin{abstract}
${ }^{\dagger}$ Department of Biochemistry and Cellular and Molecular Biology, University of Tennessee, Walters Life Sciences Building, 1414 Cumberland Avenue, Knoxville, Tennessee 37996, United States States
\end{abstract} \\ ${ }^{\ddagger}$ Department of Biochemistry and Molecular Biology, University of Southern Denmark, 55 Campusvej, 5000 Odense M, Denmark \\ ${ }^{\S}$ Department of Biological Sciences, Louisiana State University, A221 Life Sciences Annex, Baton Rouge, Louisiana 70803, United
}

Supporting Information

ABSTRACT: Plasminogen activator inhibitor type 1 (PAI-1) regulates the fibrinolysis pathway by inhibiting the protease activity of plasminogen activators. PAI-1 works in concert with vitronectin (VN), an extracellular protein that aids in localization of active PAI-1 to tissues. The Peterson laboratory demonstrated that $\mathrm{Cu}$ (II) and other transition metals modulate the stability of PAI-1, exhibiting effects that are dependent on the presence or absence of the somatomedin B (SMB) domain of VN. The study presented here dissects the changes in molecular dynamics underlying the destabilizing effects of $\mathrm{Cu}(\mathrm{II})$ on PAI-1. We utilize backbone amide hydrogen/deuterium exchange monitored by mass spectrometry to assess PAI- 1 dynamics in the presence and absence of $\mathrm{Cu}(\mathrm{II})$ ions with and without the SMB domain of $\mathrm{VN}$. We show that $\mathrm{Cu}(\mathrm{II})$ produces an increase in dynamics in regions important for the function and overall stability of PAI-1, while the SMB domain elicits virtually the opposite effect. A mutant form of PAI-1 lacking two N-terminal histidine residues at positions 2 and 3 exhibits similar increases in dynamics upon $\mathrm{Cu}(\mathrm{II})$ binding compared to that of active wild-type PAI-1, indicating that the observed structural effects are not a result of coordination of $\mathrm{Cu}$ (II) to these histidine residues. Finally, addition of $\mathrm{Cu}$ (II) results in an acceleration of the local unfolding kinetics of PAI-1 presumed to be on pathway to the latency conversion. The effect of ligands on the dynamics of PAI-1 adds another intriguing dimension to the mechanisms for regulation of PAI-1 stability and function.

$\mathrm{T}$ he physiological processes of blood clot formation (coagulation) and subsequent breakdown (fibrinolysis) are activated by highly specific serine protease cascades. ${ }^{1}$ The activity of these proteases is subject to tight regulation to maintain hemostasis. Plasminogen activator inhibitor type 1 (PAI-1) is a primary regulator of the fibrinolytic pathway. ${ }^{2}$ PAI1 is a member of the serine protease inhibitor (serpin) family and specifically inhibits tissue-type plasminogen activator (tPA) and urokinase plasminogen activator (uPA), controlling hemostasis, wound healing, matrix remodeling, and cell proliferation and differentiation. $^{3-5}$ Dysregulation of PAI-1 leads to numerous diseases in humans. While elevated levels of PAI-1 result in thrombosis ${ }^{6}$ and fibrosis in various tissues, including liver, kidney, lung, and skin, ${ }^{3}$ depletion of PAI-1 results in a hyperfibrinolytic state characterized by mild bleeding and impaired wound healing. ${ }^{7}$ However, PAI-1 deficiency and elevated levels of functional plasminogen activators in macrophages, in tandem with altered signaling pathways, also lead to tissue-specific cardiac fibrosis. ${ }^{8}$ These somewhat paradoxical findings illustrate an intricate regulatory network involving PAI-1 and multiple downstream effects that result in a variety of tissue-specific pathologies. ${ }^{3}$ Furthermore, PAI-1 regulates endothelial cell migration ${ }^{9}$ via a mechanism that is not dependent on its anti-protease activity and is linked to cancer and inflammatory diseases via complex mechanisms.

PAI-1 achieves specific and rapid inhibition of serine proteases $(\mathrm{tPA} / \mathrm{uPA})$ through a solvent-exposed loop termed the reactive center loop $(\mathrm{RCL})^{10}$ that contains the scissile bond recognized as the natural protease substrate. Upon interaction with the protease, PAI-1 traps a covalent acyl-enzyme intermediate in a stable complex through a mechanism that invokes a profound conformational rearrangement and insertion of the RCL into central $\beta$-sheet $\mathrm{A}^{11}$ Interestingly, PAI-1 RCL insertion spontaneously occurs even in the absence of proteases $\left(t_{1 / 2} \sim 1-2 \mathrm{~h}\right)^{12}$ to form a latent, inactive state ${ }^{13}$ (Figure 1). Thus, PAI-1 possesses inherent metastability, a hallmark of serpin activity that drives the structural change that traps and inactivates the protease. ${ }^{11}$ Nonetheless, few serpins incur the structural rearrangement to latency in the absence of a protease; this latency conversion of PAI-1 is shared with antithrombin and, to a lesser extent, neuroserpin. ${ }^{14,15}$ The process of latency transition is not completely understood at

Received: March 21, 2016

Revised: July 8, 2016

Published: July 14, 2016 


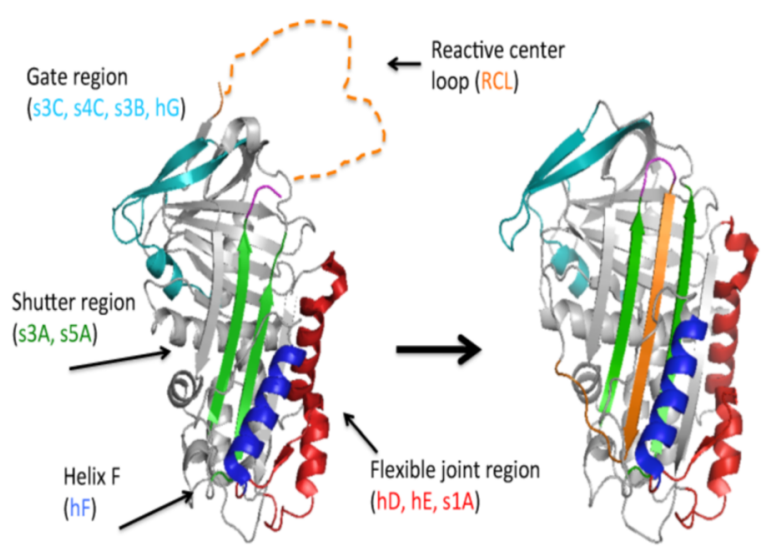

Figure 1. PAI-1 exists in an active and latent conformation. The active form of PAI-1 is shown on the left (PDB entry 3Q02), and the latent form of PAI-1 is shown on the right (PDB entry 1DVN). The RCL (orange) acts as bait for proteases in the active form where it is solvent-exposed; it is inserted into central B-sheet A in the latent form. Several steps in the mechanism of the transition to the latent form have been proposed, ${ }^{9}$ and it appears that local unfolding within key regions is involved. ${ }^{14}$ The shutter region (green) expands, and the gate region loops (teal) rearrange during the RCL insertion that occurs during the latency conversion. Helix F (blue) may be displaced temporarily during unfolding of the hydrophobic core and/or rearrangement in the bottom half of the shutter when the RCL is added as an additional strand in the central $\beta$-sheet. The flexible joint region (red) is an important site for PAI-1 protein-protein interactions, including binding of the SMB domain. ${ }^{15}$ This view of the molecule will be the standard reference orientation, with the RCLcontaining pole of PAI- 1 termed the "top" and central $\beta$-sheet A termed the "front". The nomenclature for secondary structure is as follows: hA-hI are $\alpha$-helices $\mathrm{A}-\mathrm{I}$, respectively; s1A is strand 1 of $\beta$ sheet $\mathrm{A}, \mathrm{s} 6 \mathrm{~B}$ is strand 6 of $\beta$-sheet $\mathrm{B}$, etc.

the molecular level. As an absolute minimum, the structural rearrangement requires detachment of $\mathrm{s} 1 \mathrm{C},{ }^{16}$ opening of the gate region between the $\mathrm{s} 3 \mathrm{C}-\mathrm{s} 4 \mathrm{C}$ and $\mathrm{s} 3 \mathrm{~B}-\mathrm{hG}$ loops, ${ }^{13}$ opening of the shutter region between strands s3A and s5A, and displacement of $\mathrm{hF}^{13,17}$ (Figure 1). Recently, transient unfolding of the hydrophobic core of PAI-1 was documented and proposed to play a role in the conversion to the latent form. ${ }^{18}$ The flexible joint region $(\mathrm{hD}, \mathrm{hE}$, and $\mathrm{s} 1 \mathrm{~A})$ contains the site of regulatory protein-protein interactions. ${ }^{19,20}$ A benefit of the metastable feature of PAI-1 is that it allows for conformational fine-tuning by different ligands. PAI-1 associates tightly with the glycoprotein vitronectin (VN) in the circulation, specifically at sites of injury. ${ }^{21} \mathrm{VN}$ localizes PAI-1 to fibrin matrices and inflamed tissues, and it modestly stabilizes PAI- 1 in its active form (approximately 1.5 -fold). ${ }^{22}$ PAI- 1 also has been shown to be stabilized by certain mutations, $\mathrm{pH}$, a high salt concentration, and aptamers. ${ }^{23-25}$

Other PAI-1 ligands, including transition metal ions, such as $\mathrm{Cu}(\mathrm{II}), \mathrm{Ni}(\mathrm{II})$, and $\mathrm{Co}(\mathrm{II})$, accelerate the latency transition $\left(t_{1 / 2} \sim 10-20 \mathrm{~min}\right)$. The destabilizing effect of these metal ions on PAI-1 is, however, abrogated in the presence of the somatomedin B (SMB) domain of VN. ${ }^{12}$ Stopped-flow fluorescence measurements determined a dissociation constant of $90 \mathrm{nM}$ for PAI-1 and $\mathrm{Cu}$ (II) ions. ${ }^{26}$ This affinity is well within the range of physiological relevance given that micromolar $\mathrm{Cu}$ (II) concentrations have been measured in the brain, cerebrospinal fluid, and liver. ${ }^{27,28}$ Interestingly, imbalances in metal homeostasis ${ }^{29}$ lead to several of the same disease states that occur due to dysfunction of serpins, most notably inflammatory states, metabolic syndrome, and atherosclerosis. ${ }^{30}$ We aim to understand the molecular basis for the effect of metal ions on PAI-1 conformational and functional stability, as it may play a role in these disease states. We are also interested in determining whether changes in local dynamics due to ligand binding influence the global conformational state of PAI-1. This issue is of upmost importance for fully understanding the role of serpins in disease states.

Prior studies using hydrogen/deuterium exchange monitored by mass spectrometry (HDX-MS) have shown that wild-type PAI-1 is highly dynamic; apart from a protected $\beta$-sheet B core, many regions rapidly reach complete exchange. ${ }^{31}$ Ligands such as the SMB domain of vitronectin, Mab-1 antibody, and RNA aptamers extend the length of time PAI-1 remains active. ${ }^{12,32,24}$ Expectedly, ligand binding protects against isotopic exchange in the binding interface, but the protected regions generally extend beyond the binding interface. ${ }^{31,33}$ For example, binding of the SMB domain significantly protects against exchange in peptides spanning $\mathrm{hE}$ and $\mathrm{s} 1 \mathrm{~A}$, comprising the binding interface. In addition, the $\mathrm{SMB}$ domain protects against exchange in $\mathrm{hB}, \mathrm{hC}, \mathrm{hD}, \mathrm{s} 2 \mathrm{~A}, \mathrm{hF}, \mathrm{s} 3 \mathrm{~A}, \mathrm{~s} 5 \mathrm{~A}$, and hI. Thus, SMB domain binding confers stabilization on peptides spanning the better part of the bottom pole of the molecule. ${ }^{31}$ Furthermore, mutations that stabilize PAI-1 in the active form (14-1b containing $\mathrm{N} 150 \mathrm{H}, \mathrm{K} 154 \mathrm{~T}, \mathrm{Q} 319 \mathrm{~L}$, and M354I substitutions) also result in reduced dynamics, particularly in peptides near the mutations $(\mathrm{hF}, \mathrm{s} 2 \mathrm{C}$, and $\mathrm{s} 6 \mathrm{~A})$, but also in more remote regions $\left(\mathrm{hB}, \mathrm{hC}, \mathrm{hE}, \mathrm{s} 1 \mathrm{~A}, \mathrm{hI}, \mathrm{s} 2 \mathrm{~B}\right.$, and s3B). ${ }^{31}$ Compared with the relatively stable serpins neuroserpin and $\alpha$ 1 -antitrypsin, the active form of PAI- 1 is more dynamic in the key functional regions thought to be involved in the latency transition. ${ }^{31}$ Additionally, HDX has been used to detect partial unfolding events within the hydrophobic core of PAI- ${ }^{18}$ that offer new insight into how PAI-1 converts from the active to latent form.

The recently completed crystal structure (PDB entry 3Q02) features a zinc ion bound to two N-terminal histidines ( $\mathrm{H} 2$ and H3) of one PAI-1 molecule and carboxylate-containing residues (E212, D222, E350, and E242) from the gate region of a second PAI-1 molecule, forming an asymmetric dimer interface. ${ }^{34}$ To determine whether $\mathrm{H} 2$ and $\mathrm{H} 3$ of PAI-1 coordinate $\mathrm{Cu}(\mathrm{II})$ and mediate structural effects, we have also created and analyzed a mutant form of PAI-1 that has alanine substitutions for the two N-terminal histidine residues (H2AH3A-PAI-1).

We hypothesize that ligands govern PAI-1 conformational stability through fine-tuning of protein dynamics. In this work, we have investigated several unanswered questions using hydrogen/deuterium exchange methods. Does $\mathrm{Cu}$ (II) binding increase the dynamics in regions of PAI-1 tied to latency transition? Are these regions stabilized in the presence of $\mathrm{Cu}$ (II) and the SMB domain of VN? Are the effects of $\mathrm{Cu}(\mathrm{II})$ specifically targeted to the active form? Here, we have found that $\mathrm{Cu}(\mathrm{II})$ binding increases the dynamics in structurally correlated regions of active wild-type PAI-1 (wtPAI-1). These regions are similar to those that have been targeted to reduce PAI-1 dynamics and stabilize PAI-1 in the active form by mutagenesis, addition of $\mathrm{VN}$, antibodies, or aptamers. The structurally correlated regions include the flexible joint region and shutter region, as well as $\mathrm{hI}, \mathrm{hB}$, and $\mathrm{hC}$.

\section{MATERIALS AND METHODS}

PAI-1 Protein Expression and Purification. Recombinant wild-type and mutant PAI-1 proteins were produced using 
pET-24d expression plasmid DNA transformed into Escherichia coli Rosetta 2(DE3)pLysS cells (Novagen-EMD) using the heat-shock method. Colonies were grown on agar plates containing kanamycin and chloramphenicol. Polymerase chain reaction-based site-directed mutagenesis was performed using a Quiksite mutagenesis kit (Agilent) with primers designed (Invitrogen/Life Technologies) to incorporate triplet codons necessary to express the desired mutations corresponding to histidine to alanine mutations at residues 2 and 3. Mutagenesis was confirmed by DNA sequencing. Transfer of a single colony to liquid culture was followed by growth and subculture in a larger volume at $37^{\circ} \mathrm{C}$ with shaking at $250 \mathrm{rpm}$. As the optical density $\left(\mathrm{OD}_{600}\right)$ approached 1.0 absorption unit, the temperature was reduced from 37 to $15^{\circ} \mathrm{C}$ and protein expression was induced by addition of $1 \mathrm{mM}$ IPTG (Research Products International, RPI) to the Terrific Broth cell culture medium (RPI).

Wild-type PAI-1 protein was purified with a three-column procedure as described in ref 12: Sulfopropyl (SP) Sepharose for cation exchange eluted with an ammonium sulfate gradient, nickel-charged chelating Sepharose for immobilized metal affinity (IMAC) eluted with an imidazole gradient, and gel filtration (S-100) Sephacryl to separate impurities from the final preparation. The mutant $\mathrm{H} 2 \mathrm{~A} / \mathrm{H} 3 \mathrm{~A}-\mathrm{PAI}-1$ form of the protein purification utilized a phenyl Sepharose column instead of the IMAC step using a reverse salt gradient. Pure PAI-1 mutant and wild-type proteins were passed over a catalytically inactive tPA (S478A) column (Molecular innovations) ${ }^{35}$ and eluted with 1.5 $\mathrm{M} \mathrm{NaCl}$ in $0.5 \mathrm{M}$ sodium acetate to ensure the active conformation was isolated for analysis. Polyacrylamide gel electrophoresis confirmed the formation of a 1:1 stoichiometric complex of PAI-1 and tPA in stable complexes.

Vitronectin Protein Fragment Expression and Purification. The vitronectin fragment SMB domain was produced using the pET-32b plasmid transformed into Rosetta-gami 2(DE3)pLysS cells equipped to fold disulfide-bonded proteins. The DNA sequences encoded thioredoxin protein fused $\mathrm{N}$ terminally to the $\mathrm{VN}$ sequence along with a six-His tag, which was connected by a region encoding a thrombin cleavage site; this construct is denoted Trx-SMB. Transformation and colony selection occurred as described above from agar plates containing ampicillin and chloramphenicol. After initial growth in medium containing tetracycline in addition to the aforementioned antibiotics, cells were subcultured to larger volumes at $37{ }^{\circ} \mathrm{C}$ while being shaken at $300 \mathrm{rpm}$. The temperature was then lowered to $20^{\circ} \mathrm{C}$, and after adaptation, the cultures were induced with $1 \mathrm{mM}$ IPTG for overnight protein expression.

Purification involved first isolating Trx-SMB using IMAC and eluting isocratically with $1 \mathrm{M}$ imidazole. After dialysis to remove imidazole and the transition to thrombin cleavage buffer, biotinylated thrombin was added to liberate VN fragments from His-tagged thioredoxin. Thrombin was removed by incubation with streptavidin agarose beads followed by gel filtration. Final purification of the properly disulfide-bonded VN fragments was accomplished using an active PAI-1 affinity column. The column contained active PAI1 with a single tryptophan to phenylalanine mutation at residue 175 , located in the loop C-terminal of s3A. This mutant form of PAI-1 remains active 3-4-fold longer than wtPAI-1 but maintains similar thermodynamic characteristics. ${ }^{34}$ The capacity of these constructs to inhibit binding of wild-type PAI-1 to immobilized VN was determined with surface plasmon resonance using a CM5 chip. $^{12}$

Hydrogen/Deuterium Exchange Reactions. Proteins were diluted into a preincubation buffer, containing $5 \mathrm{mM}$ MOPS, $100 \mathrm{mM}\left(\mathrm{NH}_{4}\right)_{2} \mathrm{SO}_{4}, 6.5 \mathrm{mM} \mathrm{NaCl}, 2 \mathrm{mM}$ sodium acetate, and $0.1 \mathrm{mM}$ EDTA $(\mathrm{pH} \mathrm{7.4})$ at $25{ }^{\circ} \mathrm{C}$. This yielded PAI- 1 at $5 \mu \mathrm{M}$, wherein the buffering and salt components were balanced to an identical composition among all experimental permutations. This allowed complex formation and/or quick exposure to $\mathrm{Cu}(\mathrm{II})$ ions prior to addition of deuterium $\left(\mathrm{D}_{2} \mathrm{O}\right)$ buffer. For the copper experiments, the buffer also included 215 $\mu \mathrm{M} \mathrm{CuSO}_{4}$. The $\mathrm{pH}$ of this buffer was adjusted to 7.4 at $25{ }^{\circ} \mathrm{C}$ using $\mathrm{NaOH}$ after copper addition. Because buffers exhibit significant binding of metals, we have relied on known metal/ buffer binding constants, as described in our previous work. ${ }^{26}$ Using known first-sphere buffer/metal ion affinity values, $\beta_{1}{ }^{36-38}$ the dissociation constant for metal ions in MOPS was calculated using the equation $10^{\beta_{1}}=K_{a}$ where $K_{\mathrm{a}}=1 / K_{\mathrm{d}}$. First-sphere MOPS $/ \mathrm{Cu}(\mathrm{II})$ affinity $\beta_{1}$ equals $4.00 .^{36}$ The free metal ion concentration was then determined using the quadratic equation $M_{\mathrm{f}}=M_{\mathrm{t}}-\left\{M_{\mathrm{t}}+B_{\mathrm{t}}+K_{\mathrm{d}}-\left[\left(M_{\mathrm{t}}+B_{\mathrm{t}}+\right.\right.\right.$ $\left.\left.\left.K_{\mathrm{d}}\right)^{2}-4 B_{\mathrm{t}} M_{\mathrm{t}}\right]^{1 / 2}\right\} / 2$, where $M_{\mathrm{f}}$ is the free metal concentration, $M_{\mathrm{t}}$ is the total metal ion concentration, $B_{\mathrm{t}}$ is the total buffer concentration, and $K_{\mathrm{d}}$ is the dissociation constant between the metal ion and buffer. Note that EDTA is present to prevent trace metal ion effects and for protein stability; it was subtracted from the total metal concentration before the free metal ion calculation. For experiments including the SMB domain, there was a 2 -fold molar excess $(10 \mu \mathrm{M})$ relative to the PAI-1 concentration. Preincubation solutions $(8 \mu \mathrm{L})$ were diluted 20-fold (final volume of $160 \mu \mathrm{L}$ ) into deuterium buffer [5 mM MOPS, $100 \mathrm{mM}\left(\mathrm{NH}_{4}\right)_{2} \mathrm{SO}_{4}, 6.5 \mathrm{mM} \mathrm{NaCl}, 2 \mathrm{mM}$ sodium acetate, and $0.1 \mathrm{mM}$ EDTA $(\mathrm{pD} 7.8)$ at $25^{\circ} \mathrm{C}$ ] and incubated at $25^{\circ} \mathrm{C}$, and time point samples $(10,30,180$, and $600 \mathrm{~s})$ were obtained by quenching with $1.38 \%(3.2 \mu \mathrm{L})$ formic acid and flash-freezing in liquid nitrogen.

Quenched samples were subjected to proteolytic digestion using $16 \mu \mathrm{L}$ of pepsin (final concentration of $0.5 \mathrm{mg} / \mathrm{mL}$ ) for 2 min on ice prior to injection. The entire sample was immediately injected using an ice-cold Hamilton syringe into a cooled Acquity HDX liquid chromatography system (Waters, Milford, MA). Peptides were loaded onto a Vanguard BEH C18, $2 \mathrm{~mm} \times 5 \mathrm{~mm}$ precolumn (Waters) with a flow rate of $300 \mu \mathrm{L} / \mathrm{min}$ and then eluted through an Acquity BEH $1 \mathrm{~mm} \times$ $100 \mathrm{~mm} \mathrm{C} 18$ analytical column using a gradient of 8 to $15 \% \mathrm{~B}$ over $0.5 \mathrm{~min}, 15$ to $35 \% \mathrm{~B}$ over $5.5 \mathrm{~min}$, and 35 to $85 \% \mathrm{~B}$ over $0.5 \mathrm{~min}$ at a flow of $40 \mu \mathrm{L} / \mathrm{min}$ into the mass spectrometer. Peptide ions were analyzed on a Waters Synapt G1 quadrupole time-of-flight (Q-TOF) mass spectrometer. The instrument was calibrated daily to $3 \mathrm{ppm}$ accuracy or lower. Undeuterated wild-type and mutant PAI-1 were subjected to tandem $\left(\mathrm{MS}^{2}\right)$ CID fragmentation to identify each peptic peptide to be analyzed using MASCOT (Matrix science). The average mass of each peptide in every experimental run was calculated by the following equation: average mass $=\sum_{i}\left(m_{i} I_{i}\right) /\left(\sum_{i} I_{i}\right)$, where $i$ is the isotope peak and runs from 1 to the total number of isotope peaks in the isotopic envelop, $M_{i}$ is the centroid mass of isotope peak $i$, and $I_{i}$ is the intensity of isotope peak $i$.

Deuterium uptake plots were generated by plotting the average mass shift for each peptide against the logarithm of the incubation time. Normalized uptake was calculated from experimental samples with respect to fully deuterated controls (100\%). Fully deuterated control peptides were generated by 
incubation of PAI-1 in $4 \mathrm{M}$ deuterated guanidinium chloride in $\mathrm{D}_{2} \mathrm{O}$ for $4 \mathrm{~h}$, followed by identical reaction quenching, treatment, and analysis. Each protected amide hydrogen in a protein can be found in a closed, open, or exchanged state (closed $\leftrightarrow$ open $\rightarrow$ exchanged), where closed and open refer to cases in which the amide hydrogen participates in a hydrogen bond and does not, respectively. The rate of opening is $k_{\text {open }}$, while the rate of closing is $k_{\text {close; the rate of hydrogen/ }}$ deuterium exchange when the amide hydrogen is in the open state is $k_{\mathrm{ch}}$ (ch for chemical exchange rate). The EX2-type exchange limit (EX2 kinetics) is defined as the limit at which the rate of closing is much faster than the rate of chemical exchange, or $k_{\text {close }} \gg k_{\text {ch }}$. EX2 kinetics is the most common type of exchange observed in well-folded proteins. In this regime, many opening events are required for each exchange event, and the result is a gradual mass shift of one isotope population in the spectra as a function of isotope exchange time. The EX1 exchange limit (EX1 kinetics) is defined as the limit at which the chemical exchange rate is much higher than the rate of closing, or $k_{\mathrm{ch}} \gg k_{\text {close }}$. In this regime, the overall rate of deuterium incorporation becomes equal to $k_{\text {open }}$. EX1-type exchange kinetics is less commonly observed, but when it occurs, it yields characteristic broadening of the isotopic distribution or even a bimodal isotope distribution reflecting an unfolding event. If isotope populations in such a bimodal distribution are sufficiently separated in mass (deuterium content), it is possible to deduce the rate of unfolding as it is equal to the rate at which the low-mass population interchanges with the high-mass population. For a further explanation of EX1 and EX2 kinetics, see ref 39.

Isothermal Titration Calorimetry (ITC). ITC directly detects the heat exchange in a protein-ligand interaction to determine enthalpy changes $(\Delta H)$, stoichiometries $(n)$, and the dissociation constant $\left(K_{\mathrm{d}}\right)$ of interaction. For ITC experiments, PAI-1 and SMB domain stocks were buffer exchanged into 50 $\mathrm{mM}$ MOPS and $250 \mathrm{mM}\left(\mathrm{NH}_{4}\right)_{2} \mathrm{SO}_{4}(\mathrm{pH} \mathrm{7.4})$ at $10{ }^{\circ} \mathrm{C}$. To achieve buffer matching of PAI-1 and copper(II) solutions, PAI-1 was dialyzed for $2 \mathrm{~h}$ under the aforementioned buffer conditions, and copper(II) solutions $(300 \mu \mathrm{M})$ were made from the dialysate. Addition of copper(II) sulfate resulted in a drop in $\mathrm{pH}$, so solutions were adjusted back to $\mathrm{pH} 7.4$ at $10{ }^{\circ} \mathrm{C}$ using $\mathrm{NaOH}$. ITC was performed using $20 \mu \mathrm{M}$ W175F PAI-1, with and without 1.2 molar equivalents of the SMB domain (24 $\mu \mathrm{M})$. Protein samples $(2.2 \mathrm{~mL})$ and copper(II) samples $(4 \mathrm{~mL})$ were degassed for $5 \mathrm{~min}$ at $10{ }^{\circ} \mathrm{C}$ prior to being loaded into the Microcal VP-ITC instrument. The PAI-1 sample was loaded into the $1.394 \mathrm{~mL}$ volume ITC cell, for which the baseline temperature was set to $10^{\circ} \mathrm{C}$ for the entirety of the experiment. The copper(II) solution was loaded into the syringe and injected into the cell in 54 increments. Each injection was $5 \mu \mathrm{L}$ in volume, over $2 \mathrm{~min}$ intervals, using a total of 54 total injections. Control experiments in which the copper solution of the same concentration $(300 \mu \mathrm{M})$ was injected into buffer in the ITC sample cell were performed. The heats of each injection in the control experiment were subtracted from the data from experiments that included protein. The data were then baseline-corrected using NITPIC software (University of Texas Southwestern Medical Center, Dallas, TX) prior to data analysis. The data were fit to a two-site nonsymmetric binding model using SEDPHAT (National Institutes of Health, Bethesda, MD).

\section{RESULTS}

Adaptation of the HDX-MS Method Is Needed To Measure Metal Ion Effects. The previous HDX-MS work using N-terminally histidine-tagged PAI-1 and phosphatebuffered saline $(\mathrm{PBS})^{31}$ employed unsuitable conditions for these metal ion studies of wild-type PAI-1. We have expressed PAI-1 without the N-terminal histidine tag, as it introduces an engineered metal-binding site that is non-native to PAI-1. In our previous work on metal ion effects with PAI- $1,{ }^{12,26}$ we avoided using PBS because the phosphate salts of the metal ions have very low solubility and adopted therefore either a Tris or MOPS buffer system. Furthermore, buffers have been observed to have modest effects on the stability of PAI-1, but more importantly, buffers have widely varying affinities for metal ions themselves. ${ }^{26}$ MOPS buffer proved to be preferable in previous stopped-flow kinetic measurements because of the tight binding exhibited by copper(II) and PAI- $1,{ }^{26}$ so this was the buffer of choice for the HDX experiments.

We thus determined whether experimental conditions using MOPS and wild-type PAI-1 yield reproducible HDX results compared with previous work. ${ }^{31,33}$ HDX was performed on wild-type PAI-1 and histidine-tagged PAI-1 in both PBS and MOPS buffer for comparison. We observed that the presence or absence of an N-terminal histidine tag has no effect on PAI-1 dynamics in each buffer; results for all peptides were compared, and peptide $64-92(\mathrm{hD}-\mathrm{S} 2 \mathrm{~A})$ is shown as an example from the data set (Figure S1). While the HDX results were comparable in PBS buffer for both forms of PAI-1, a surprising 20\% reduction in the level of deuterium uptake was generally observed using the MOPS buffer system. We attribute this reduction in the level of $\mathrm{D}$ uptake to the presence of the ammonium sulfate component of the buffer, which is known to have a stabilizing effect on proteins. The only exception to this trend was observed with highly dynamic peptides that were fully deuterated within the experimental time frame.

Moreover, the reduction of the level of deuterium uptake in MOPS versus PBS buffer offers an advantage for observing differences in $\mathrm{HDX}$ that will arise from ligands like $\mathrm{Cu}$ (II) that increase protein dynamics. In PBS, many peptides reach fully exchanged levels very quickly, so the dynamic range in HDX experiments on PAI- 1 is expanded using the MOPS buffer to slow the exchange. However, a MOPS concentration of $50 \mathrm{mM}$ in the HDX-MS experiments caused severe chromatographic interference during the reversed-phase chromatographic separation of peptic peptides. The conditions finalized for HDX-MS experiments therefore used $5 \mathrm{mM}$ MOPS at $25^{\circ} \mathrm{C}$, yielding conditions with a longer half-life for PAI- $1\left(t_{1 / 2}=257\right.$ $\pm 11 \mathrm{~min})$ as expected because of temperature effects. The separate effects of $\mathrm{Cu}(\mathrm{II})$ and the SMB domain on PAI-1 in 5 mM MOPS buffer at $25{ }^{\circ} \mathrm{C}$ are qualitatively similar to those reported in Tris buffer, with $t_{1 / 2}$ values of $\sim 418.3 \pm 13 \mathrm{~min}$ for PAI-1 with the SMB domain, $\sim 49.3 \pm 6$ min for PAI-1 with $\mathrm{Cu}(\mathrm{II})$, and $424.7 \pm 50 \mathrm{~min}$ for PAI-1 with the SMB domain and $\mathrm{Cu}(\mathrm{II})$. Unexpectedly, the difference in half-life comparing the conditions with the SMB domain versus the SMB domain with $\mathrm{Cu}(\mathrm{II})$ was negligible. Thus, these experimental conditions for HDX-MS are optimal for measuring differences in exchange upon $\mathrm{Cu}(\mathrm{II})$ binding versus SMB domain binding but are not sensitive for comparing the dynamic effects of the SMB domain versus the $\mathrm{SMB}$ domain with $\mathrm{Cu}(\mathrm{II})$. For the sake of completeness, the half-life of PAI-1 was also measured at a higher MOPS concentration of $50 \mathrm{mM}$ (which is not suitable 
a)

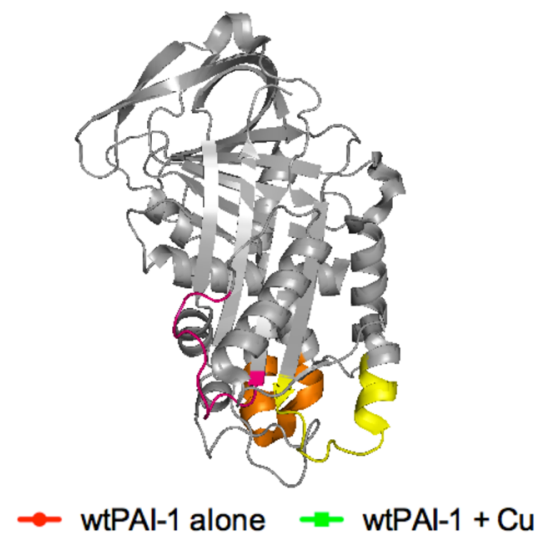

c)

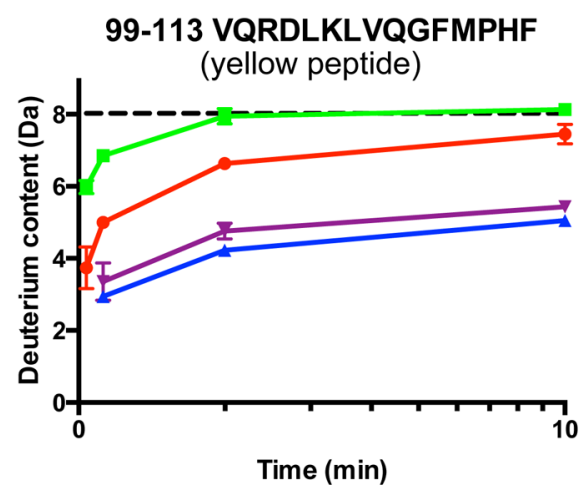

b)

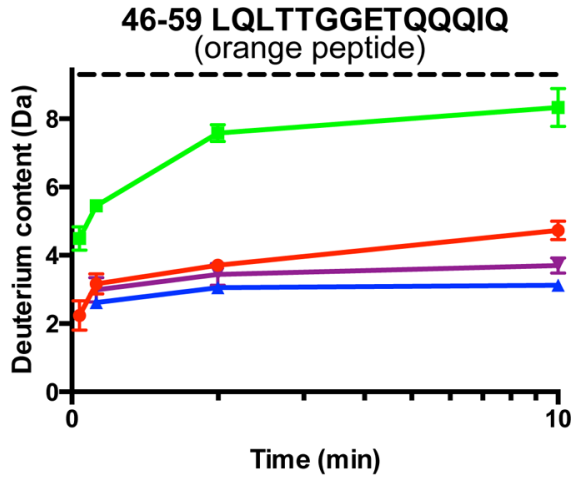

$w \mathrm{tPAl}-1+\mathrm{SMB} \rightarrow \mathrm{wtPAl}-1+\mathrm{SMB}+\mathrm{Cu}$

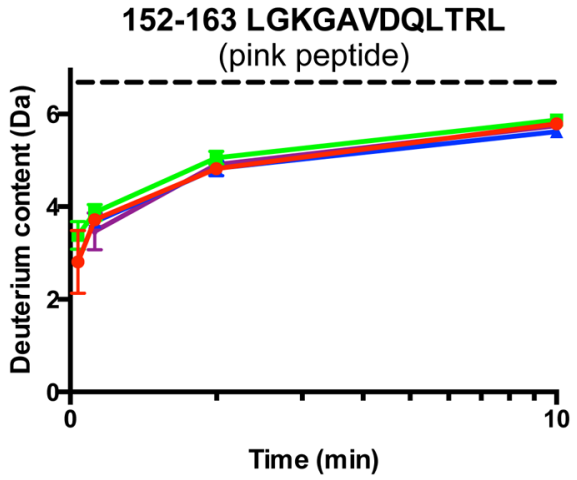

Figure 2. Representative data from HDX-MS for active wtPAI-1. (a) Structure of PAI-1 showing the locations of three representative peptides. The peptide spanning residues $46-59 \mathrm{of} \mathrm{hB}, \mathrm{hC}$, and the loop between them is colored orange. The peptide spanning residues $99-113$ of the C-terminal end of s2A, hE, and the loop between them is colored yellow. The peptide spanning residues $152-163$ of the N-terminal part of s3A and part of the preceding loop connected to $\mathrm{hF}$ is colored teal. (b-d) Representative deuterium uptake plots comparing the effects of addition of $\mathrm{Cu}$ (II) (with or without the SMB domain). Deuterium uptake plots are shown for three PAI-1 peptides: 46-59 (LQLTTGGETQQQIQ) in panel b, 99-113 (FVQRDLKLVQGFMPHF) in panel c, and 152-163 (LGKGAVDQLTRL) in panel d. HDX-MS experiments were conducted using wtPAI-1 (red), wtPAI-1 and $\mathrm{Cu}(\mathrm{II})$ (green), wtPAI-1 and the SMB domain (blue), and wtPAI-1, the SMB domain, and Cu(II) (purple). Deuterium uptake plots show the increase in mass units for the individual peptides over time for the individual samples.

for HDX-MS experiments). The effects of $\mathrm{Cu}(\mathrm{II})$ and the SMB domain on PAI-1 in $50 \mathrm{mM}$ MOPS buffer at $37^{\circ} \mathrm{C}$ are similar to those reported in Tris buffer, with $t_{1 / 2}$ values of $70.7 \pm 3.6$ min for PAI-1, $126.2 \pm 4.3 \mathrm{~min}$ for PAI-1 with the SMB domain, $38.3 \pm 1.0 \mathrm{~min}$ for PAI-1 with $\mathrm{Cu}$ (II), and $170.9 \pm 2.1$ min for PAI-1 with the SMB domain and $\mathrm{Cu}$ (II). Interestingly, under these conditions, $\mathrm{Cu}$ (II) causes a prolonged half-life of PAI-1 when the SMB domain is bound, as reported previously. ${ }^{12}$ The underlying reason for the different effects of $\mathrm{Cu}(\mathrm{II})$ on the stability of PAI-1 under different buffer concentrations and temperature is not yet clear.

Addition of Copper(II) Increases Dynamics in Important Regions of PAI-1. The effect of $\mathrm{Cu}(\mathrm{II})$ ions on the backbone dynamics of active wtPAI-1 was probed in the presence and absence of the SMB domain of VN. Deuterium uptake plots for these experiments are presented in Figure S2. Representative deuterium uptake plots are shown in Figure 2 to illustrate the effects of $\mathrm{Cu}$ (II) on three representative PAI-1 peptides generated by peptic cleavage. Unligated active wtPAI-1 is highly dynamic. Peptides comprising the lower backside underlying the shutter ( $\mathrm{hB}$ and $\mathrm{hC})$, flexible joint region $(\mathrm{hD}$, $\mathrm{hE}$, and s1A), shutter region ( $\mathrm{s} 3 \mathrm{~A}$ and $\mathrm{s} 5 \mathrm{~A}$ ), and gate region (s3C, s4C, and s3B) experience substantial deuterium uptake over the experimental time course (Figure S2). Consistent with previous work, ${ }^{31}$ the only regions predominantly protected from exchange exist in $\beta$-sheet $\mathrm{B}$ in the protein core. Also consistent with previous work, ${ }^{31}$ addition of the SMB domain of $\mathrm{VN}$ resulted in widespread stabilization of the flexible joint region and the backside, constituting the majority of the lower half of the molecule (Figure S2). In contrast, addition of $\mathrm{Cu}$ (II) leads to increased exchange rates for peptides in many of these regions. As shown in the representative plots in panels $b$ and $c$ of Figure 2, addition of $\mathrm{Cu}$ (II) results in an increase in the level of deuterium incorporation, consistent with increased dynamics in regions covered by peptides 46-59 and 99-113, compared with active wtPAI-1 alone. In line with previous reports, ${ }^{31}$ binding of PAI-1 by the SMB domain resulted in protection against exchange, consistent with reduced structural dynamics in the regions covered by these peptides. When both the SMB domain and $\mathrm{Cu}(\mathrm{II})$ are added to PAI-1, similar results are observed relative to the SMB domain addition alone for the peptides displayed in Figure 2. Peptide 152-163 represents an example of a peptide that is unaffected by the addition of $\mathrm{Cu}$ (II) the presence or absence of the SMB domain (Figure 2d).

We observed numerous PAI-1 peptides that exhibited an increase in the level of deuterium uptake as a result of $\mathrm{Cu}$ (II) binding, and it was informative as a first step to localize these changes within the primary sequence of PAI-1. To facilitate this analysis, the relative deuterium content, presented as a percent of the full deuteration level, was calculated for each peptide, with and without $\mathrm{Cu}(\mathrm{II})$ bound to PAI-1, and the difference in 

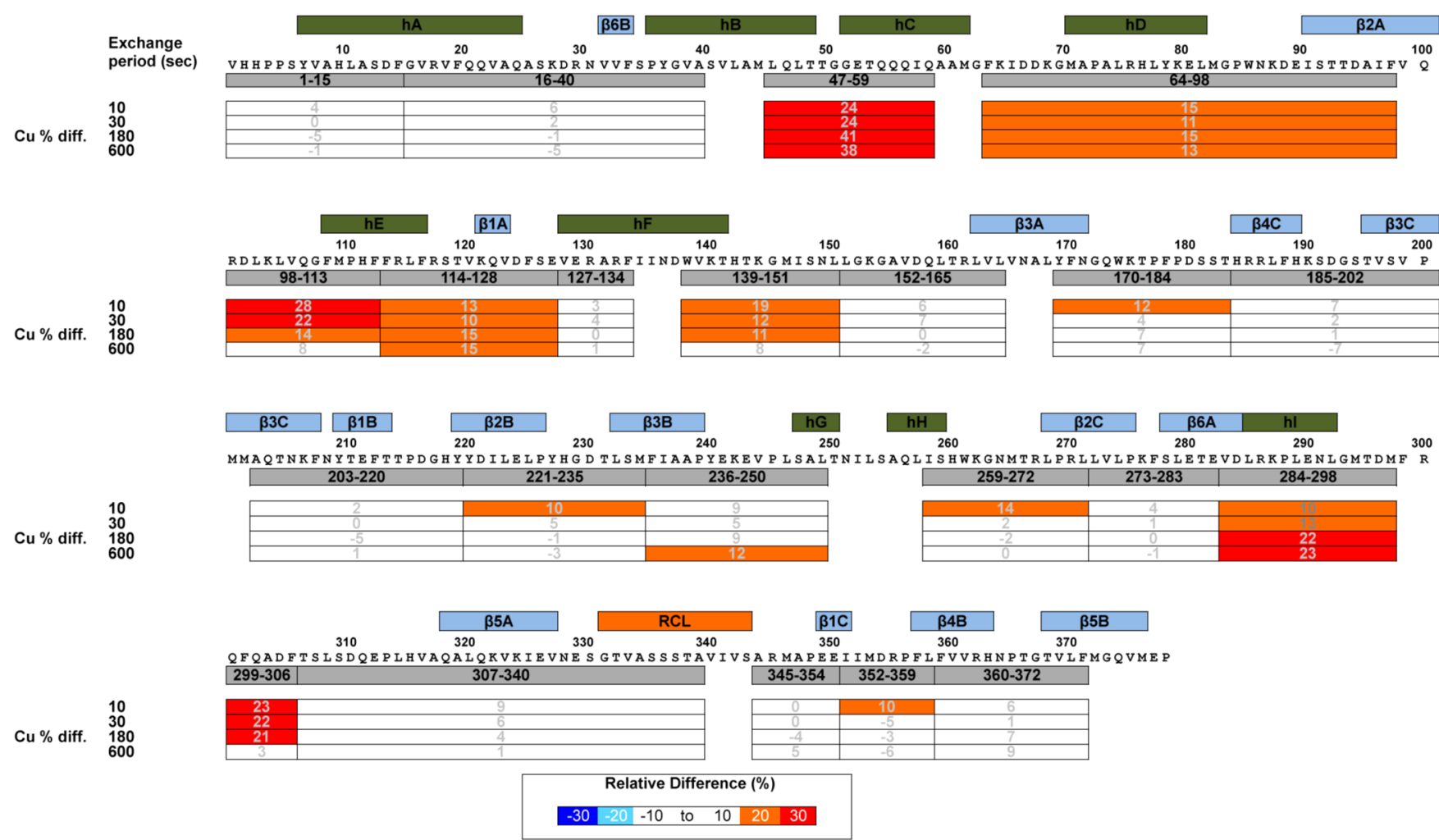

Figure 3. Effects of $\mathrm{Cu}(\mathrm{II})$ on PAI-1 dynamics via a look at the primary structure. HDX-MS data were collected for various exchange periods listed at the far left. For each of the four time points, deuterium exchange is given as a percentage relative to that observed for wtPAI- 1 alone. The data with or without $\mathrm{Cu}(\mathrm{II})$ were normalized with respect to a $(100 \%)$ fully deuterated control in which the protein is subjected to guanidine denaturation in $\mathrm{D}_{2} \mathrm{O}$ for $4 \mathrm{~h}$ to determine the extent of deuterium exchange for unfolded protein. The primary structure of PAI- 1 is shown along the top of each row, with secondary structure elements noted as $\alpha$-helices (green) and $\beta$-strands (blue). The identity of individual peptic peptides that were analyzed is shown in the gray boxes along the sequence, and uptake results for each peptide at the four time points are shown in the columns below each peptide. Note that the proteolysis yields peptides spanning most of the PAI-1 sequence, giving essentially complete coverage in the HDX-MS experiments. The observed deuterium uptake values are the percentage difference between the two experimental conditions ([wtPAI- $1+\mathrm{Cu}]-$ [wtPAI-1 alone]). The normalized percent difference was color-coded as follows: dark blue for a percent difference of less than $-20 \%$, light blue for -20 to $10 \%$, white for -10 to $10 \%$, orange for $10-20 \%$, and red for $>20 \%$.

relative deuterium content was plotted as a heat map along the primary sequence (Figure 3). Peptide 46-59 (hB-hC loop) exhibited a high level of exchange in the presence of $\mathrm{Cu}(\mathrm{II})$, indicative of an increase in dynamics in this region underlying the shutter. Immediately following this peptide in the sequence, peptides covering the flexible joint region [64-94 (hC-hD), 99-113 (s2A-hE), 114-128 (hE-s1A), and 139-151 (hF)] also have increased exchange consistent with elevated dynamics. In addition, peptides spanning residues 284-298 (s6A-hI) and 299-306 (loop between hI and s5A), immediately preceding the shutter region strand $5 \mathrm{~A}$, feature increased dynamics as a result of $\mathrm{Cu}$ (II) binding. Importantly, $\mathrm{Cu}(\mathrm{II})$ binding has no effect on exchange in several regions of PAI-1. Peptides covering the first two N-terminal peptides that include $\mathrm{hA}$ and the preceding $\mathrm{N}$-terminal residues, $\beta$-sheets $\mathrm{B}$ and $\mathrm{C}, \mathrm{hG}, \mathrm{hH}$, and the $\mathrm{C}$-terminus are unaffected by $\mathrm{Cu}(\mathrm{II})$ binding in our measurements. To interpret the spatial signature of $\mathrm{Cu}$ (II) binding on PAI-1 dynamics, we transferred the heat map shown in Figure 3 onto the three-dimensional structure of PAI-1 (Figure 4a). Each of the peptic peptides affected by $\mathrm{Cu}$ (II) addition is localized to the flexible joint region and areas underlying the shutter strands of $\beta$-sheet A. Altogether, our observations using these experimental conditions indicate that $\mathrm{Cu}$ (II) binding causes localized rather than global changes in PAI-1 dynamics, on the time scale investigated. Furthermore, it is apparent that $\mathrm{Cu}(\mathrm{II})$ binding increases dynamics in regions of PAI-1 that are important for the anti-protease activity and metastable nature of PAI-1, namely, the flexible joint region and underlying helices in the shutter region.

Binding of the SMB Domain Negates the Effect of Copper(II) on the Dynamics of PAI-1. Binding of PAI-1 by the SMB domain from $\mathrm{VN}$, which houses the primary highaffinity binding site for PAI- $1,{ }^{20}$ results in significant protection against exchange in several peptides, namely, 46-59 (hB-hC), 99-113 (s2A-hE), 114-128 (hE-s1A), and 299-306 (hI loop-s5A) (Figures S2 and S3). This is consistent with previously published results, ${ }^{31}$ although the SMB domain effect is generally less pronounced in this study because of the reduced dynamics of PAI-1 in MOPS buffer compared to that in PBS. The noted peptides are located in or proximal to the flexible joint region, including the $\mathrm{SMB}$ domain-binding interface. Likewise, binding of both $\mathrm{Cu}(\mathrm{II})$ and the $\mathrm{SMB}$ domain produced similar patterns of HDX protection observed upon the binding of the SMB domain alone, a general phenomenon illustrated by the examples in panels $b$ and $c$ of Figure 2. As observed with binding of the SMB domain alone, peptides 47-59 (hB-hC), 99-113 (s2A-hE), 114-128 (hEs1A), and 299-306 (hI loop-s5A) (Figures S2 and S3) are regions highly protected from exchange when both the SMB domain and $\mathrm{Cu}(\mathrm{II})$ are bound. Mapping of the results for 


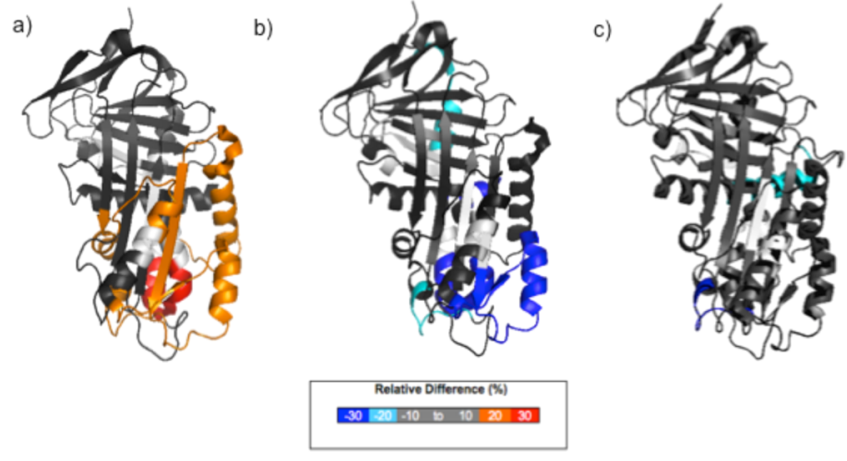

Figure 4. $\mathrm{Cu}$ (II) increases localized dynamics in the flexible joint region and underlying shutter helices, and the SMB domain negates the $\mathrm{Cu}$ (II) effects. (a) Heat map of effects of $\mathrm{Cu}$ (II) on the PAI- 1 structure. The normalized percent difference in deuterium uptake comparing wtPAI- 1 and $\mathrm{Cu}(\mathrm{II})$ versus wtPAI- 1 alone for the peptic peptides (Figure 3) was mapped onto the three-dimensional structure of active PAI-1 (PDB entry 3Q02). The percent difference in deuterium uptake is shown for the $180 \mathrm{~s}$ HDX time point, colored dark blue for less than $-20 \%$, light blue for -20 to $-10 \%$, dark gray for -10 to $10 \%$, orange for $10-20 \%$, and red for $>20 \%$. Areas of light gray represent peptides for which there was no sequence coverage. (b) Heat map of effects of $\mathrm{Cu}(\mathrm{II})$ and the SMB domain on the PAI- 1 structure. The normalized percent difference in deuterium uptake comparing wtPAI-1 with the SMB domain and $\mathrm{Cu}(\mathrm{II})$ vs wtPAI-1 alone for peptic peptides (Figure S2) was mapped onto the threedimensional structure of active PAI-1 (PDB entry $3 \mathrm{Q} 02$ ). The percent difference in deuterium uptake is shown for the $180 \mathrm{~s} \mathrm{HDX}$ time point, colored dark blue for less than $-20 \%$, light blue for -20 to $-10 \%$, dark gray for -10 to $10 \%$, orange for $10-20 \%$, and red for $>20 \%$. Areas of light gray represent peptides for which there was no sequence coverage. (c) Heat map depicting effects of $\mathrm{Cu}$ (II) with the SMB domain compared to the binding of the SMB domain alone on the PAI-1 structure. The normalized percent difference in deuterium uptake comparing wtPAI-1 with the SMB domain and $\mathrm{Cu}(\mathrm{II})$ vs wtPAI-1 and the SMB domain for peptic peptides (Figure S2) was mapped onto the three-dimensional structure of active PAI-1 (PDB entry $3 \mathrm{Q} 02$ ). The percent difference in deuterium uptake is shown for the $180 \mathrm{~s}$ HDX time point, colored dark blue for less than $-20 \%$, light blue for -20 to $-10 \%$, dark gray fr -10 to $10 \%$, orange for $10-20 \%$, and red for $>20 \%$. Areas of light gray represent peptides for which there was no sequence coverage.

binding of the SMB domain and $\mathrm{Cu}(\mathrm{II})$ shows similar protection patterns observed with binding of the SMB domain alone $^{31}$ and shows reduced dynamics in the flexible joint region (Figure 4b).

However, some differences in exchange that distinguish binding of the SMB domain alone from binding of the SMB domain and $\mathrm{Cu}(\mathrm{II})$ were apparent. As shown in Figure 4c, the $\mathrm{N}$-terminal peptide (residues $1-15$ ) was substantially protected upon binding of both the SMB domain and $\mathrm{Cu}(\mathrm{II})$ in contrast to the protection seen for the binding of the SMB domain alone. The change in HDX exchange behavior observed upon binding of the combination of the SMB domain and $\mathrm{Cu}$ (II) is sublocalized to residues 8-15, which exhibits protection (Figure S2). The $\mathrm{N}$-terminal histidine residues in positions 2 and 3 constitute one of the $\mathrm{Cu}$ (II)-binding sites on PAI-1 (see below), but binding of copper(II) to this peptide does not perturb its exchange behavior. Indeed, it should be noted that peptide 1-7 is not differentially affected by binding of any of the ligands, presumably because it is highly dynamic at the extreme $\mathrm{N}$-terminus of the protein. Although it is likely that there are additional changes that lead to reduced dynamics behavior in PAI-1 upon binding of the combination of the SMB domain and $\mathrm{Cu}(\mathrm{II})$, the experiments conducted here may not reveal these. The lower exchange rate in MOPS at $25^{\circ} \mathrm{C}$, under conditions geared to probe $\mathrm{Cu}$ (II) binding effects and increases in dynamics, is suboptimal for detecting further decreases in dynamics beyond those invoked by binding of the SMB domain alone. Taken together, our data show that both with and without $\mathrm{Cu}(\mathrm{II})$, the binding of the $\mathrm{SMB}$ domain protects against dynamic changes that are correlated with the accelerated latency conversion that is induced upon the binding of $\mathrm{Cu}(\mathrm{II})$ alone.

Importantly, the high affinity of $\mathrm{Cu}$ (II) for PAI-1, previously measured with a $K_{\mathrm{d}}$ of $<100 \mathrm{nM},^{26}$ appears to be unaffected upon the binding of the SMB domain. This is apparent from isothermal titration calorimetry experiments (Figure S4) in which the $\mathrm{Cu}$ (II) binding isotherm is unchanged comparing PAI-1 and the PAI-1-SMB domain complex. Our ongoing work has demonstrated that there are multiple binding sites for metal ions on PAI-1, including two high-affinity sites. The fit to the ITC data in Figure S4 shows that these two high-affinity binding sites, each with a $K_{\mathrm{d}}$ of $<30 \mathrm{nM}$, remain unperturbed in the presence of the bound $\mathrm{SMB}$ domain. Also, there is no binding of $\mathrm{Cu}(\mathrm{II})$ to the isolated $\mathrm{SMB}$ domain detected by calorimetry (not shown). Thus, the changes in dynamics observed in these HDX experiments are due to binding and conformational effects of the SMB domain and $\mathrm{Cu}(\mathrm{II})$ and not to changes in affinity, which would alter saturation levels. Furthermore, it is clear that the changes in HDX observed in the presence and absence of the SMB domain are not due to competition for metal binding.

Copper(II) Affects Protein Dynamics in the Same Regions within H2AH3A-PAl-1 and Wild-Type PAI-1. As the recent crystal structure of W175F PAI-1 revealed a zinc positioned proximal to the two N-terminal histidines of PAI-1 at positions 2 and 3 in the protein chain (PDB entry 3Q02), experiments were designed to assess whether $\mathrm{Cu}$ (II) asserts its effect on PAI-1 dynamics through binding to these same residues. A form of PAI-1 was engineered with alanine substitutions for these two histidines, and HDX experiments were performed to test for the effects of $\mathrm{Cu}$ (II) on dynamics. The representative uptake plot in panels $\mathrm{a}$ and $\mathrm{b}$ of Figure 5 compares $\mathrm{H}-\mathrm{D}$ exchange rates for active wtPAI- 1 with those for active H2AH3A-PAI-1 in the presence and absence of $\mathrm{Cu}(\mathrm{II})$. Data are shown for peptides $46-59(\mathrm{hB}-\mathrm{hC}$ loop) and 99-113 (hE-s1A) as illustrative examples. Uptake plots for the entire set of HDX measurements with H2AH3A-PAI-1 with and without addition of $\mathrm{Cu}(\mathrm{II})$ are shown in Figure S5. Comparing wild-type PAI-1 to H2AH3A-PAI-1 revealed a decrease in HDX rates as a result of incorporation of this double amino acid substitution into PAI-1 (Figure 5a,b). Also, as with wild-type PAI-1, the mutant shows an increase in the rate of deuterium exchange in the presence of $\mathrm{Cu}(\mathrm{II})$ compared with that of H2AH3A-PAI-1 alone. Across the primary sequence, changes in dynamics due to $\mathrm{Cu}$ (II) addition occur in similar regions seen with active wild-type PAI-1 upon $\mathrm{Cu}$ (II) binding (Figure S6). The regions that experience changes are apparent when the $\mathrm{Cu}(\mathrm{II})$ effects are mapped onto the structure of H2AH3A-PAI-1 (Figure 5c). The peptides spanning the $\mathrm{hB}-\mathrm{hC}$ loop, $\mathrm{hD}, \mathrm{hE}, \mathrm{hF}, \mathrm{hI}$, and $\mathrm{s} 5 \mathrm{~A}$ all have increased rates of exchange due to $\mathrm{Cu}$ (II) addition, as observed with wild-type PAI-1 (Figure 4a).

From a structural perspective, mutant and wild-type PAI-1 are affected by $\mathrm{Cu}(\mathrm{II})$ in largely similar regions, including the 
a)

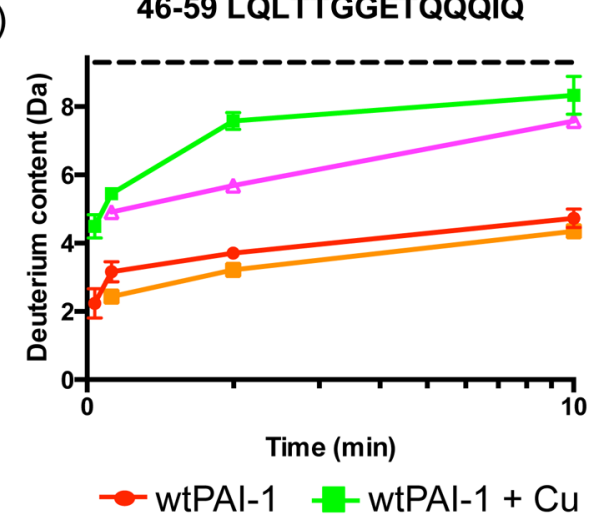

c)

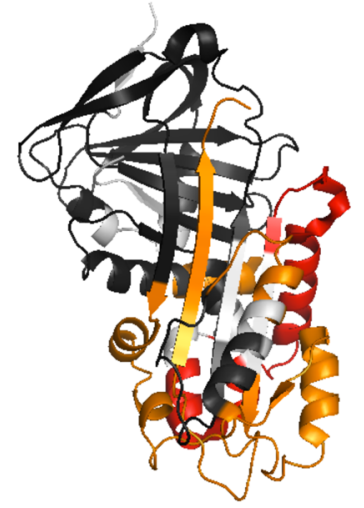

b)

99-113 VQRDLKLVQGFMPHF

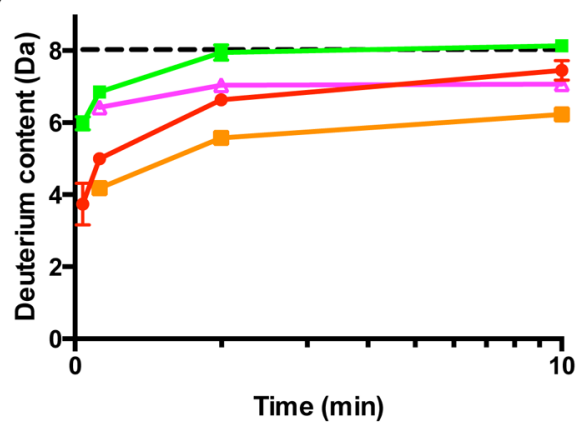

d)

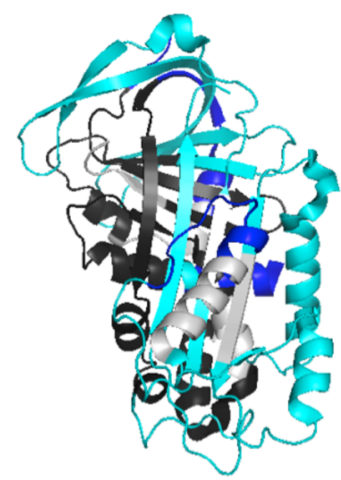

e)

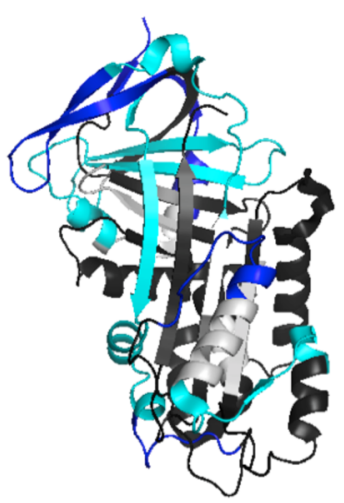

Relative Difference (\%)

Figure 5. Evaluating the effects of addition of $\mathrm{Cu}(\mathrm{II})$ on H2AH3A-PAI-1 dynamics. (a and b) Deuterium uptake plots for two PAI-1 peptides in H2AH3A-PAI-1 and wtPAI-1:(a) peptide 46-59 (LQLTTGGETQQQIQ) and (b) peptide 99-113 (FVQRDLKLVQGFMPHF). HDX-MS experiments were conducted using wtPAI-1 (red), wtPAI-1 and $\mathrm{Cu}(\mathrm{II})$ (green), H2AH3A-PAI-1 (purple), and H2AH3A-PAI-1 and Cu(II) (orange). Deuterium uptake plots show the increase in mass units for the individual peptides over time. (c) Heat map of effects of Cu(II) on the H2AH3A-PAI-1 structure. The normalized percent difference in deuterium uptake comparing H2AH3A-PAI-1 and Cu(II) vs H2AH3A-PAI-1 alone for the peptic peptides (Figure S6) was mapped onto the three-dimensional structure of active PAI-1 (PDB entry 3Q02). The percent difference in deuterium uptake is shown for the 180 s HDX time point, colored dark blue for less than $-20 \%$, light blue for -20 to $-10 \%$, dark gray for -10 to $10 \%$, orange for $10-20 \%$, and red for $>20 \%$. Areas of light gray represent peptides for which there was no sequence coverage. (d) Structural heat map of H2AH3A-PAI-1 dynamics compared with that of wtPAI-1. The normalized percent difference in deuterium uptake comparing H2AH3A-PAI1 vs wtPAI-1 for the peptic peptides was mapped onto the three-dimensional structure of active PAI-1 (PDB entry 3Q02). The percent difference in deuterium uptake is shown for the $180 \mathrm{~s}$ HDX time point, colored dark blue for less than $-20 \%$, light blue for -20 to $-10 \%$, dark gray for -10 to $10 \%$, orange for $10-20 \%$, and red for $>20 \%$. Areas of light gray represent peptides for which there was no sequence coverage. (e) Structural heat map of effects of $\mathrm{Cu}(\mathrm{II})$ on H2AH3A-PAI-1 compared with wtPAI-1. The normalized percent difference in deuterium uptake comparing H2AH3APAI-1 and $\mathrm{Cu}$ (II) vs wtPAI-1 and $\mathrm{Cu}$ (II) for the peptic peptides was mapped onto the three-dimensional structure of active PAI-1 (PDB entry $3 \mathrm{Q} 02)$. The percent difference in deuterium uptake is shown for the $180 \mathrm{~s}$ HDX time point, colored dark blue for less than $-20 \%$, light blue for -20 to $-10 \%$, dark gray for -10 to $10 \%$, orange for $10-20 \%$, and red for $>20 \%$. Areas of light gray represent peptides for which there was no sequence coverage.

flexible joint region and helices that border the shutter region, although there are some differences. Figure $5 \mathrm{~d}$ shows the difference in dynamics comparing H2AH3A-PAI-1 and wildtype PAI without ligands, and Figure 5e shows the differences mapped onto the structure for the two forms of the protein with added $\mathrm{Cu}(\mathrm{II})$. The decreased dynamics in H2AH3A-PAI-1 at multiple sites in the protein are apparent, in the presence or absence of $\mathrm{Cu}$ (II). One intriguing difference of note between the mutant and wild-type PAI- 1 is observed with peptides $1-15$ and $8-15(\mathrm{hA})$ that include the mutated residues. These peptides are protected from exchange in the presence of $\mathrm{Cu}$ (II) and the SMB domain in wtPAI-1 but show no differences when $\mathrm{Cu}$ (II) alone is added to wtPAI-1 (Figure S2). Conversely, addition of $\mathrm{Cu}(\mathrm{II})$ results in an increase in the rate of exchange for the same peptides in H2AH3A-PAI-1. Apart from this difference, the overall response in dynamics to $\mathrm{Cu}(\mathrm{II})$ binding is quite similar for wtPAI- 1 and $\mathrm{H} 2 \mathrm{AH} 3 \mathrm{~A}-\mathrm{PAI}-1$, suggesting that the $\mathrm{Cu}$ (II)-induced destabilization is not mediated by the binding of $\mathrm{Cu}$ (II) to the two N-terminal histidines of PAI-1.

Copper(II) Has Modest Effects on the Dynamics of the Latent Form of wtPAI-1. Previous binding studies showed that metals bind to both the active and latent forms of PAI-1, albeit with differing affinities. ${ }^{26}$ It is therefore important to determine whether $\mathrm{Cu}$ (II) affects the dynamics of both the active and latent form of PAI-1. HDX studies were thus pursued with latent wild-type PAI-1 in the presence and absence of added $\mathrm{Cu}(\mathrm{II})$. In the absence of $\mathrm{Cu}$ (II), results from peptides throughout PAI-1 illustrate an almost global reduction in HDX rates that accompanies the conformational change to the latent form, consistent with previous work, ${ }^{31}$ as shown in 
Active wtPAI-1 alone [peptide 46-63] in MOPS $25^{\circ} \mathrm{C}$

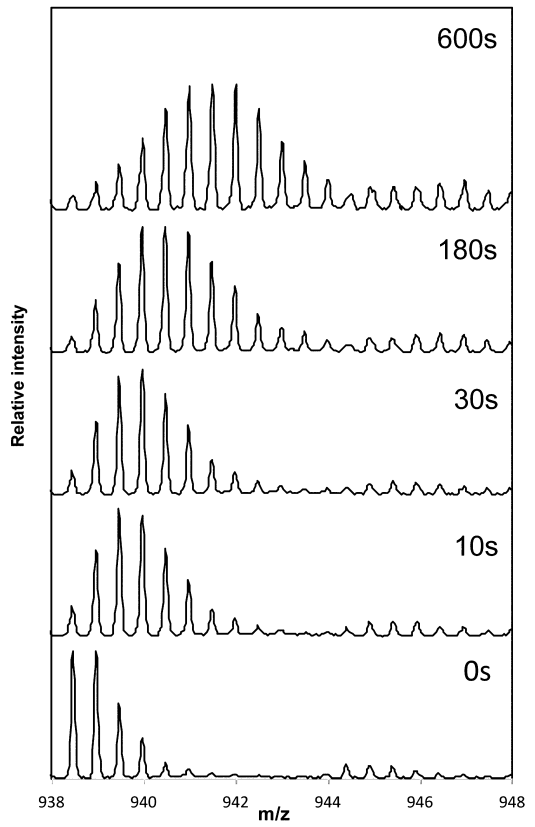

Active wtPAI-1 + Copper [peptide $46-63$ ] in MOPS $25^{\circ} \mathrm{C}$

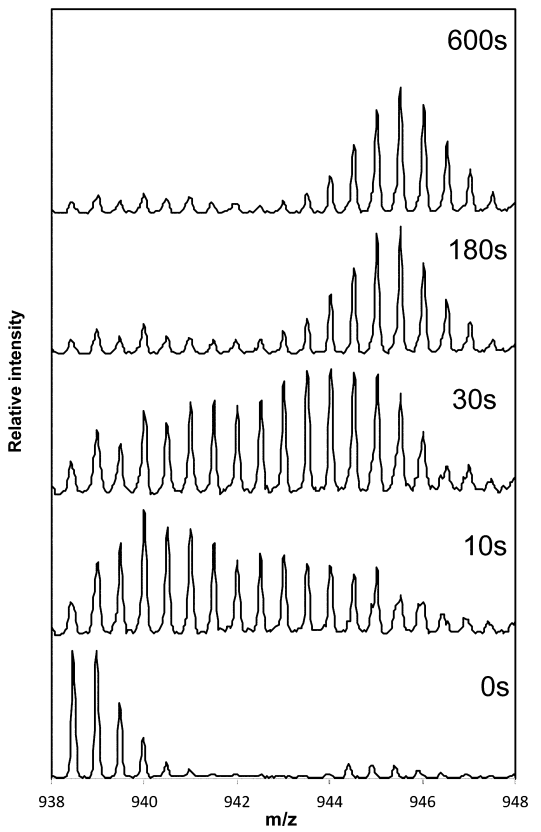

Figure 6. Local unfolding kinetics of PAI-1 peptide 46-63 accelerated in the presence of $\mathrm{Cu}(\mathrm{II})$. The isotopic envelopes for active wtPAI- 1 alone (left) and active wtPAI-1 and $\mathrm{Cu}$ (II) (right) are shown in duplicate for HDX time points 10, 30, 180, and $600 \mathrm{~s}$. The data shown are from the peptic peptide (residues 46-63), underlying shutter strands s3A and s5A, under both experimental conditions.

the deuterium uptake for all peptides (Figure S7), also illustrated by representative uptake plots of peptides $46-59$ (hB-hC loop) and 99-113 (s2A-hE) (Figure S8), and the map across primary sequence (Figure S9). The sample uptake plots in Figure S8 compare active wtPAI-1 in the presence and absence of $\mathrm{Cu}(\mathrm{II})$ with latent wtPAI- 1 in the presence and absence of $\mathrm{Cu}(\mathrm{II})$. A view of the effect of $\mathrm{Cu}$ (II) on latent wildtype PAI- 1 is illustrated by the three-dimensional rendering shown in Figure S8. While there are modest changes in dynamics for a few peptides, the differences are not localized to one region on the structure; nor are they located in regions known to influence latency conversion or protease inactivation.

Copper(II) Accelerates Local Unfolding of a Peptide in the hB-hC Region on a Time Scale Relevant for the Latency Transition. Recently, HDX-MS was used to reveal local unfolding events in PAI-1 peptides that occur on time scales relevant to latency conversion. ${ }^{18}$ The signature of an unfolding event in the HDX-MS data is the presence of bimodal isotope distributions (see Materials and Methods for further explanation). In the case of a transient unfolding event, protein molecules that have not yet visited the unfolded state will yield a low-mass population in the mass spectrum, whereas protein molecules that have visited the unfolded state will yield a high-mass population. The mass difference between the two populations is proportional to the number of backbone amide hydrogens exposed to the solvent as a consequence of the unfolding event. The rate of unfolding can be measured as the rate at which the low- and high-mass populations interconvert. Three peptides detected in the HDX-MS experiments on PAI-1 displayed this effect: $46-63(\mathrm{hB}-\mathrm{hC})$ with a $t_{1 / 2}$ of $\sim 80 \mathrm{~s}$ at 15 ${ }^{\circ} \mathrm{C}\left(<10 \mathrm{~s}\right.$ at $\left.37^{\circ} \mathrm{C}\right), 16-40(\mathrm{hA}-\mathrm{s} 6 \mathrm{~B})$ with a $t_{1 / 2}$ of $\sim 18 \mathrm{~min}$ at $37^{\circ} \mathrm{C}$, and $307-340(\mathrm{~s} 5 \mathrm{~A})$ with a $t_{1 / 2}$ of $\sim 24 \mathrm{~min}$ at $37^{\circ} \mathrm{C}$. ${ }^{18}$ $\mathrm{Cu}$ (II) binding increases the rate of the latency transition, and we thus reasoned that $\mathrm{Cu}$ (II) might assert this effect through acceleration of these transient unfolding events. As the HDX experiments conducted here were performed at $25{ }^{\circ} \mathrm{C}$ in MOPS buffer and terminated after exchange for $10 \mathrm{~min}$, we did not sample the appropriate time and temperature to observe the unfolding of regions covered by peptides $16-40$ and 307340. The unfolding previously observed in the $\mathrm{hB}-\mathrm{hC}$ peptide was much more frequent and is therefore sampled in the experiments conducted here (Figure 6). Interestingly, the change to MOPS buffer decreased the rate of unfolding significantly, and only a negligible fraction of molecules have visited the unfolded state after incubation for $10 \mathrm{~min}$ as judged by the limited peak broadening. Most importantly, addition of $\mathrm{Cu}(\mathrm{II})$ accelerates the unfolding event substantially $\left(t_{1 / 2} \sim 20\right.$ $\mathrm{s})$, and the spacing between the two mass populations resembles that previously observed when PAI-1 was analyzed in PBS. This means that addition of $\mathrm{Cu}(\mathrm{II})$ not only counteracts the effect of MOPS on the rate of unfolding but also forces the geometric extent of unfolding in the region to revert to that observed in PBS. As expected, we also observed this bimodal peak distribution in the mutant H2AH3A-PAI-1 (data not shown). Taken together, the correlation between accelerated local unfolding and accelerated latency transition upon addition of $\mathrm{Cu}(\mathrm{II})$ to PAI-1 further supports the hypothesis that unfolding events contribute in significant ways to the mechanism by which active PAI-1 rearranges to the latent inactive conformation.

\section{DISCUSSION}

Copper(II) Increases Dynamics in Regions Similar to Those Affected by the SMB Domain. Cu(II) accelerates the latency conversion of PAI-1, while the presence of the SMB domain of $\mathrm{VN}$ negates the destabilizing effect of $\mathrm{Cu}$ (II). Because the SMB domain restricts dynamics of PAI- 1 , ${ }^{31}$ we hypothesized that addition of $\mathrm{Cu}$ (II) would increase the level of deuterium exchange if protein dynamics play an influential role in the rate of conversion. This hypothesis is supported by the 
observation that the same PAI-1 regions that are stabilized by SMB domain binding are the regions in which dynamics are enhanced upon binding $\mathrm{Cu}(\mathrm{II})$. The flexible joint region, gate region, and shutter region are known to mediate steps in the mechanism for the conformational transition of PAI- 1 from the active to latent form. ${ }^{12,26}$ We observed changes in dynamics in largely overlapping regions affected by binding of the SMB domain as well as $\mathrm{Cu}$ (II), including the flexible joint region, and the $\mathrm{N}$-terminal part of $\mathrm{hF} .{ }^{13} \mathrm{We}$ also observed changes due to $\mathrm{Cu}$ (II) in the area underlying the shutter in the $\mathrm{hB}-\mathrm{hC}$ peptide and a proximal hI peptide. Importantly, the altered dynamics did not manifest globally but were localized to key regions. In other words, some dynamic, as well as protected, regions within PAI-1 experienced no changes as a result of $\mathrm{Cu}(\mathrm{II})$ binding in our experiments.

Metal ions have a unique effect on PAI-1, characterized by the ability to promote or prevent the latency transition at higher buffer concentrations, depending on binding of the cofactor vitronectin. The binding of $\mathrm{Cu}$ (II) accelerates the latency transition $^{12}$ and strongly increases the rate of HDX for peptides spanning helices $\mathrm{hB}, \mathrm{hC}$, and hI. Although no other ligands with this unusual property have been identified, mutagenesis approaches have provided insights into the importance of the shutter and the $\mathrm{hB}-\mathrm{hC}$ peptide for the latency transition. For example, amino acid substitutions that disrupt a hydrogen bonding network in the shutter region increase latency conversion rates, ${ }^{40}$ with altered sensitivity to vitronectin as a stabilizing protein. Also, a substitution for K323 in $\beta$-strand $5 \mathrm{~A}$ in the vicinity of the shutter resulted in differential effects in the presence and absence of vitronectin. ${ }^{40}$ Interestingly, monoclonal antibody binding can modulate the vitronectin effects in unexpected ways, particularly with the K323A mutant. ${ }^{41}$ Previous biochemical and HDX studies using the Mab-l antibody ${ }^{32}$ and aptamers ${ }^{24}$ designed to stabilize PAI1 in the active form targeted the flexible joint region, but also helices hB, hC, and hI of PAI-1. ${ }^{24}$ Addition of Mab-1 and aptamers stabilized PAI- 1 in the active form by 1.4 -fold ${ }^{32}$ and 3-4-fold, ${ }^{24}$ respectively. Strikingly, peptides spanning this region also exhibited decreased rates of exchange in the presence of the Mab-1 antibody, ${ }^{31}$ aptamers, ${ }^{33}$ and the SMB domain, $^{31}$ albeit with differing protection patterns for the various ligands. Taken together with our data on copper(II) ion effects, these findings further support the hypothesis that dynamics of $\mathrm{hB}, \mathrm{hC}$, and $\mathrm{hI}$ play a role in latency conversion ${ }^{33}$

Our results feature more protection than in previous studies, caused by the buffer optimization from PBS to MOPS for metal ion studies. This switch was vital for maintaining an appropriate dynamic window for PAI-1 in the presence of a ligand that increases the rate of exchange. In the previous studies conducted in PBS, many peptides reached fully deuterated levels within the first time points. ${ }^{31}$ The propensity of phosphate to precipitate divalent metal ions meant that PBS was not an option for our studies and allowed us to observe $\mathrm{Cu}$ (II) effects that increased HDX rates relative to that of the unligated protein. On the other hand, the slower exchange rates in the MOPS buffer system limited our ability to measure differences at the other extreme. For example, binding of the SMB domain protected the flexible joint region but was less dramatic in MOPS relative to HDX with PAI-1 alone compared to previous results in PBS. ${ }^{31}$ Upon binding to the SMB domain and $\mathrm{Cu}(\mathrm{II})$ concurrently, PAI-1 remains in the active form longer than with the SMB domain alone at $50 \mathrm{mM}$ MOPS and $37{ }^{\circ} \mathrm{C}$. However, using the conditions designed for the HDX study ( $5 \mathrm{mM}$ MOPS at $25{ }^{\circ} \mathrm{C}$ ), no additional stabilization of SMB domain-bound PAI-1 was observed upon ligation with $\mathrm{Cu}(\mathrm{II})$. Nevertheless, the MOPS buffer system incurring a general stabilizing structural effect on PAI-1 slowed exchange rates and narrowed the effective window for measuring decreases in HDX-MS, as expected upon binding the combination of the $\mathrm{SMB}$ domain and $\mathrm{Cu}(\mathrm{II})$. Half-lives for PAI-1 vary somewhat with buffering agents, but the observed trends whereby the SMB domain of vitronectin decreases rates of latency conversation are consistent.

N-Terminal Histidines of PAl-1 Do Not Mediate Changes in Dynamics Affected by Copper(II). We previously identified the $\mathrm{N}$-terminal histidines as well as gate region (E212, D222, E350, and E242) carboxylates as potential targets for metal coordination in the most recent PAI- 1 crystal structure determination. ${ }^{34}$ In this study, we tested the hypothesis that $\mathrm{Cu}(\mathrm{II})$ binds at the $\mathrm{N}$-terminal site and leads to increases in dynamics. If the two histidines were critical for coordinating $\mathrm{Cu}(\mathrm{II})$, then mutation of these residues would eliminate $\mathrm{Cu}$ (II)-induced changes in the dynamics of PAI-1. An interesting and unexpected result is the global reduction in dynamics upon substitution of alanine for both histidine 2 and histidine 3. Nonetheless, it was clear that H2AH3A-PAI-1 follows a pattern similar to that of the wild-type protein with regard to dynamic changes in the presence of $\mathrm{Cu}(\mathrm{II})$. Altogether, these data indicate that the $\mathrm{N}$-terminal histidines are not the residues that coordinate metal to produce elevated dynamics and accelerated latency transition kinetics.

Latent wtPAl-1 Is Insensitive to the Effects of Copper(II) on Dynamics. A global reduction in dynamics was observed upon comparison of active and latent PAI-1, due to the conformational change that yields a more compact, rigid structure. The only region with increased exchange in the latent form of PAI- 1 is in the gate region, due to the widening of $\beta$ sheet $C$ strands that is necessary to allow the RCL to pass through during loop insertion. Addition of $\mathrm{Cu}$ (II) to latent PAI-1 resulted in modest increases in the rate of exchange from a few isolated peptides but had no effect on the flexible joint region. Addition of $\mathrm{Cu}(\mathrm{II})$ had a minimal influence on dynamics near the gate region, an area that opens as a result of a conformational shift to the latent state. Although there could be several reasons for these observations, the most likely interpretation lies at the heart of the study. That is the metastable nature of PAI- 1 that keeps it poised for protease inactivation and drives it toward a timed inactivation as it converts to a latent form. Clearly, active PAI-1 is highly dynamic and sensitive to ligands that promote changes in protein dynamics that influence the overall conformation. Latent PAI-1 is inherently restricted in dynamics and thus not as prone to effects upon ligand binding.

An Early Unfolding Event Related to the Latency Transition. As mentioned above, the need to perform experiments on $\mathrm{Cu}(\mathrm{II})$, a ligand that increases PAI-1 H-D exchange rates, required a modification of experimental conditions (temperature and buffer) to slow the exchange rates within a measurable window. This adjustment offered an opportunity for us to observe a local unfolding event that occurs in the time frame of the experiment. This is local unfolding of peptide $46-63(\mathrm{hB}-\mathrm{hC})$ that occurs with a $t_{1 / 2}$ of $80 \mathrm{~s}$ at $15^{\circ} \mathrm{C}$ and a $t_{1 / 2}$ of $<10 \mathrm{~s}$ at $37{ }^{\circ} \mathrm{C}$ in PBS buffer. ${ }^{18}$ The observation of local unfolding in this region provides some insight into the mechanism by which $\mathrm{Cu}$ (II) exerts its effect and promotes the conformational change toward latency. In 
our study, the same peptide (peptide 46-63) experiences local unfolding, in MOPS buffer in $10 \mathrm{~min}$ at $25^{\circ} \mathrm{C}$, but the experimental time scale would have to be extended to view the local unfolding kinetics completely. The addition of $\mathrm{Cu}$ (II) under these conditions decreased the $t_{1 / 2}$ to $\sim 30 \mathrm{~s}$. Because PAI-1 has a half-life for conversion to the latent form $\left(37^{\circ} \mathrm{C}\right)$ of approximately $1 \mathrm{~h}$, with a decrease to $10 \mathrm{~min}$ upon binding of $\mathrm{Cu}(\mathrm{II})$, these rates of local peptide unfolding observed by HDX likely correspond to early events in the latency transition process. The other peptides (16-40 and 299-306) have $t_{1 / 2}$ values for unfolding on the order of that of the latency transition process itself. ${ }^{18}$ It is important to note that we also observe local unfolding in peptide $46-63$ of H2AH3A-PAI-1 with $\mathrm{Cu}(\mathrm{II})$ bound, indicating that $\mathrm{Cu}(\mathrm{II})$ exerts it effects on PAI-1 by binding in positions different from a site including the two N-terminal histidines. Taken together, these results show that $\mathrm{Cu}$ (II) binding facilitates an early transition presumed to be on the pathway to latency.

\section{CONCLUSIONS}

The goal of this study was to evaluate the effects of $\mathrm{Cu}(\mathrm{II})$ on protein dynamics of several forms of PAI-1, including active wild-type PAI-1, active PAI-1 in the presence of the SMB domain, latent PAI-1, and active H2AH3A-PAI-1. PAI-1 works in complex with $\mathrm{VN}$ at sites of vascular injury to regulate hemostasis and also associates with the extracellular matrix where it has been associated with normal and disease pathologies, including inflammatory responses, tumor development, and obesity. Circulating, tissue, and extracellular reserves of $\mathrm{Cu}$ (II) play roles in these pathophysiological situations that are not well understood. Our recent discovery of unexpected effects of $\mathrm{Cu}(\mathrm{II})$ on PAI- 1 activity and stability, ${ }^{12,26}$ in a vitronectin-dependent fashion, prompted us to evaluate effects on protein dynamics that could be tied to function. Addition of physiologically relevant concentrations of $\mathrm{Cu}(\mathrm{II})$, which accelerate conversion of PAI-1 to its latent form, results in increased dynamics of PAI-1 within regions similar to those that exhibit decreased dynamics upon the binding of the SMB domain of $\mathrm{VN}$. Binding of both $\mathrm{Cu}(\mathrm{II})$ and the SMB domain together negates $\mathrm{Cu}(\mathrm{II})$ effects, resulting in patterns of protection similar to those seen when the SMB domain alone is bound. Because $\mathrm{Cu}(\mathrm{II})$ accelerates the latency transition, but the SMB domain stabilizes the active form, these data on the dynamic behavior of PAI-1 correspond nicely with the measurement of PAI-1 latency conversion in the presence of the ligands using kinetic approaches. ${ }^{12}$ In addition to many of the known structural features of PAI-1 tied to conformational stability, including the flexible joint region, shutter region, and gate region, the dynamics of helices $\mathrm{hB}, \mathrm{hC}$, and $\mathrm{hI}$ emerge as important factors that determine the rate of latency conversion. Furthermore, local unfolding observed in a peptide spanning $\mathrm{hB}$ and $\mathrm{hC}$ occurs with a half-life that is accelerated in the presence of $\mathrm{Cu}(\mathrm{II})$. The time scales indicate this local unfolding event occurs early in the latency conversion process. Observation of the unfolding upon $\mathrm{Cu}$ (II) addition suggests that PAI-1 employs a similar path to the latent state in the presence and absence of $\mathrm{Cu}(\mathrm{II})$. This study indicates that protein dynamics guide the PAI-1 latency conversion process. Comparing and contrasting among ligands that stabilize and destabilize PAI-1 show that they decrease and increase dynamics, respectively. Thus, physiologically important metal ion ligands that alter the latency transition in a $\mathrm{VN}$-dependent manner effect changes by altering protein dynamics in key regions of PAI-1. In a broader sense, our demonstration that ligands have specific effects on dynamics is particularly intriguing in the case of a metastable protein that undergoes a transition from active to inactive conformations readily under physiological conditions. These specific effects of $\mathrm{Cu}(\mathrm{II})$ on PAI-1 provide a mechanistic understanding of the unusual metal ion effects, depending on vitronectin, which can affect activity in a variety of biological settings where metals and PAI1 are tied to disease.

\section{ASSOCIATED CONTENT}

\section{Supporting Information}

The Supporting Information is available free of charge on the ACS Publications website at DOI: 10.1021/acs.biochem.6b00256.

Representative deuterium uptake levels comparing the deuterium uptake of PAI-1 with and without an Nterminal His tag in PBS buffer and MOPS buffer (Figure S1), deuterium uptake plots of active wtPAI-1 in the presence and absence of $\mathrm{Cu}(\mathrm{II})$ and the $\mathrm{SMB}$ domain (Figure S2), determination of the effect of the SMB domain and $\mathrm{Cu}(\mathrm{II})$ on PAI-1 dynamics via a look at the primary structure (Figure S3), binding of $\mathrm{Cu}(\mathrm{II})$ to active PAI-1 determinied by ITC (with and without the SMB domain) (Figure S4), deuterium uptake plots of active wtPAI- 1 versus $\mathrm{H} 2 \mathrm{AH} 3 \mathrm{~A}$ PAI- 1 in the presence and absence of $\mathrm{Cu}$ (II) (Figure S5), effect of $\mathrm{Cu}$ (II) on H2AH3A-PAI-1 dynamics (Figure S6), deuterium uptake plots of active wtPAI-1 versus latent wtPAI-1 in the presence and absence of $\mathrm{Cu}(\mathrm{II})$ (Figure S7), latent wtPAI-1 that features minimal changes in HDX in the presence and absence of $\mathrm{Cu}$ (II) (Figure S8), and determination of the effect of $\mathrm{Cu}$ (II) binding on latent PAI-1 dynamics via a look at the primary structure (Figure S9) (PDF)

\section{AUTHOR INFORMATION}

\section{Corresponding Author}

*Address: 124 Hatcher Hall, Louisiana State University, Baton Rouge, LA 70803. E-mail: cbpeterson@lsu.edu.

\section{Funding}

We gratefully acknowledge financial support by the American Heart Association (Grant 10GRNT4430033, C.B.P.) and the Danish Council for Independent ResearchlTechnology and Production Sciences (Grant 09-072885, T.J.D.J. and M.B.T.). This work was also supported by a grant from The Carlsberg Foundation (Grant 2012_01_0332, T.J.D.J.).

\section{Notes}

The authors declare no competing financial interest.

\section{ABBREVIATIONS}

HDX, hydrogen-deuterium exchange; HDX-MS, hydrogendeuterium exchange coupled to mass spectrometry; IPTG, isopropyl $\beta$-D-1-thiogalactopyranoside; H2AH3A-PAI-1, variant form of PAI-1 lacking two N-terminal histidines at positions 2 and 3 in the amino acid sequence; PDB, Protein Data Bank; $\mathrm{RCL}$, reactive center loop; $\mathrm{SMB}$, somatomedin $\mathrm{B}$; $\mathrm{tPA}$, tissuetype plasminogen activator; uPA, urokinase plasminogen activator; VN, vitronectin; wtPAI-1, wild-type plasminogen activator inhibitor 1 . 


\section{REFERENCES}

(1) Fay, W. P., Garg, N., and Sunkar, M. (2007) Vascular functions of the plasminogen activation system. Arterioscler., Thromb., Vasc. Biol. 27 (6), 1231-1237.

(2) De Taeye, B., Smith, L. H., and Vaughan, D. E. (2005) Plasminogen activator inhibitor-1: a common denominator in obesity, diabetes and cardiovascular disease. Curr. Opin. Pharmacol. 5 (2), 149154.

(3) Ghosh, A. K., and Vaughan, D. E. (2012) PAI-1 in tissue fibrosis. J. Cell. Physiol. 227 (2), 493-507.

(4) Alessi, M. C., and Juhan-Vague, I. (2006) PAI-1 and the metabolic syndrome: links, causes, and consequences. Arterioscler., Thromb., Vasc. Biol. 26 (10), 2200-2207.

(5) Carmeliet, P., Schoonjans, L., Kieckens, L., Ream, B., Degen, J., Bronson, R., De Vos, R., van den Oord, J. J., Collen, D., and Mulligan, R. C. (1994) Physiological consequences of loss of plasminogen activator gene function in mice. Nature 368 (6470), 419-424.

(6) Vaughan, D. E. (2005) PAI-1 and atherothrombosis. J. Thromb. Haemostasis 3 (8), 1879-1883.

(7) Lijnen, H. R. (2005) Pleiotropic functions of plasminogen activator inhibitor-1. J. Thromb. Haemostasis 3 (1), 35-45.

(8) Moriwaki, H., Stempien-Otero, A., Kremen, M., Cozen, A. E., and Dichek, D. A. (2004) Overexpression of urokinase by macrophages or deficiency of plasminogen activator inhibitor type 1 causes cardiac fibrosis in mice. Circ. Res. 95 (6), 637-644.

(9) Minor, K. H., and Peterson, C. B. (2002) Plasminogen activator inhibitor type 1 promotes the self-association of vitronectin into complexes exhibiting altered incorporation into the extracellular matrix. J. Biol. Chem. 277 (12), 10337-10345.

(10) Hagglof, P., Bergstrom, F., Wilczynska, M., Johansson, L. B., and Ny, T. (2004) The reactive-center loop of active PAI-1 is folded close to the protein core and can be partially inserted. J. Mol. Biol. 335 (3), 823-832.

(11) Olson, S. T., Swanson, R., Day, D., Verhamme, I., Kvassman, J., and Shore, J. D. (2001) Resolution of Michaelis complex, acylation, and conformational change steps in the reactions of the serpin, plasminogen activator inhibitor-1, with tissue plasminogen activator and trypsin. Biochemistry 40 (39), 11742-11756.

(12) Thompson, L. C., Goswami, S., Ginsberg, D. S., Day, D. E., Verhamme, I. M., and Peterson, C. B. (2011) Metals affect the structure and activity of human plasminogen activator inhibitor-1. I. Modulation of stability and protease inhibition. Protein Sci. 20 (2), $353-365$.

(13) Egelund, R., Schousboe, S. L., Sottrup-Jensen, L., Rodenburg, K. W., and Andreasen, P. A. (1997) Type-1 plasminogen-activator inhibitor - conformational differences between latent, active, reactivecentre-cleaved and plasminogen-activator-complexed forms, as probed by proteolytic susceptibility. Eur. J. Biochem. 248 (3), 775-785.

(14) Takehara, S., Onda, M., Zhang, J., Nishiyama, M., Yang, X., Mikami, B., and Lomas, D. A. (2009) The 2.1-A crystal structure of native neuroserpin reveals unique structural elements that contribute to conformational instability. J. Mol. Biol. 388 (1), 11-20.

(15) Beauchamp, N. J., Pike, R. N., Daly, M., Butler, L., Makris, M., Dafforn, T. R., Zhou, A., Fitton, H. L., Preston, F. E., Peake, I. R., and Carrell, R. W. (1998) Antithrombins Wibble and Wobble (T85M/K): archetypal conformational diseases with in vivo latent-transition, thrombosis, and heparin activation. Blood 92 (8), 2696-2706.

(16) Dupont, D. M., Blouse, G. E., Hansen, M., Mathiasen, L., Kjelgaard, S., Jensen, J. K., Christensen, A., Gils, A., Declerck, P. J., Andreasen, P. A., and Wind, T. (2006) Evidence for a pre-latent form of the serpin plasminogen activator inhibitor- 1 with a detached betastrand 1C. J. Biol. Chem. 281 (47), 36071-36081.

(17) Stout, T. J., Graham, H., Buckley, D. I., and Matthews, D. J. (2000) Structures of active and latent PAI-1: a possible stabilizing role for chloride ions. Biochemistry 39 (29), 8460-8469.

(18) Trelle, M. B., Madsen, J. B., Andreasen, P. A., and Jorgensen, T. J. (2014) Local transient unfolding of native state PAI-1 associated with serpin metastability. Angew. Chem., Int. Ed. 53 (37), 9751-9754.
(19) Jensen, J. K., Wind, T., and Andreasen, P. A. (2002) The vitronectin binding area of plasminogen activator inhibitor-1, mapped by mutagenesis and protection against an inactivating organochemical ligand. FEBS Lett. 521 (1-3), 91-94.

(20) Zhou, A., Huntington, J. A., Pannu, N. S., Carrell, R. W., and Read, R. J. (2003) How vitronectin binds PAI-1 to modulate fibrinolysis and cell migration. Nat. Struct. Biol. 10 (7), 541-544.

(21) Tweezer-Zaks, N., Ben-Horin, S., Schiby, G., Bank, I., Levi, Y., Livneh, A., and Langevitz, P. (2006) Severe gastrointestinal inflammation in adult dermatomyositis: characterization of a novel clinical association. Am. J. Med. Sci. 332 (6), 308-313.

(22) Inuzuka, S., Ueno, T., Torimura, T., Tamaki, S., Sugawara, H., Sakata, R., Kusaba, N., Sata, M., and Tanikawa, K. (1997) The significance of colocalization of plasminogen activator inhibitor-1 and vitronectin in hepatic fibrosis. Scand. J. Gastroenterol. 32 (10), 10521060.

(23) Mangs, H., Sui, G. C., and Wiman, B. (2000) PAI-1 stability: the role of histidine residues. FEBS Lett. 475 (3), 192-196.

(24) Madsen, J. B., Dupont, D. M., Andersen, T. B., Nielsen, A. F., Sang, L., Brix, D. M., Jensen, J. K., Broos, T., Hendrickx, M. L., Christensen, A., Kjems, J., and Andreasen, P. A. (2010) RNA aptamers as conformational probes and regulatory agents for plasminogen activator inhibitor-1. Biochemistry 49 (19), 4103-4115.

(25) Dupont, D. M., Madsen, J. B., Kristensen, T., Bodker, J. S., Blouse, G. E., Wind, T., and Andreasen, P. A. (2009) Biochemical properties of plasminogen activator inhibitor-1. Front. Biosci., Landmark Ed. 14, 1337-1361.

(26) Thompson, L. C., Goswami, S., and Peterson, C. B. (2011) Metals affect the structure and activity of human plasminogen activator inhibitor-1. II. Binding affinity and conformational changes. Protein Sci. 20 (2), 366-378.

(27) Allen, K. G., and Klevay, L. M. (1994) Copper: an antioxidant nutrient for cardiovascular health. Curr. Opin. Lipidol. 5 (1), 22-28.

(28) Kramer, M. L., Kratzin, H. D., Schmidt, B., Romer, A., Windl, O., Liemann, S., Hornemann, S., and Kretzschmar, H. (2001) Prion protein binds copper within the physiological concentration range. J. Biol. Chem. 276 (20), 16711-16719.

(29) Brewer, G. J. (2005) Anticopper therapy against cancer and diseases of inflammation and fibrosis. Drug Discovery Today 10 (16), $1103-1109$

(30) Iwaki, T., Urano, T., and Umemura, K. (2012) PAI-1, progress in understanding the clinical problem and its aetiology. Br. J. Haematol. 157 (3), 291-298.

(31) Trelle, M. B., Hirschberg, D., Jansson, A., Ploug, M., Roepstorff, P., Andreasen, P. A., and Jorgensen, T. J. (2012) Hydrogen/deuterium exchange mass spectrometry reveals specific changes in the local flexibility of plasminogen activator inhibitor 1 upon binding to the somatomedin B domain of vitronectin. Biochemistry 51 (41), 82568266.

(32) Bodker, J. S., Wind, T., Jensen, J. K., Hansen, M., Pedersen, K. E., and Andreasen, P. A. (2003) Mapping of the epitope of a monoclonal antibody protecting plasminogen activator inhibitor-1 against inactivating agents. Eur. J. Biochem. 270 (8), 1672-1679.

(33) Trelle, M. B., Dupont, D. M., Madsen, J. B., Andreasen, P. A., and Jorgensen, T. J. (2014) Dissecting the effect of RNA aptamer binding on the dynamics of plasminogen activator inhibitor 1 using hydrogen/deuterium exchange mass spectrometry. ACS Chem. Biol. 9 (1), 174-182.

(34) Jensen, J. K., Thompson, L. C., Bucci, J. C., Nissen, P., Gettins, P. G., Peterson, C. B., Andreasen, P. A., and Morth, J. P. (2011) Crystal structure of plasminogen activator inhibitor-1 in an active conformation with normal thermodynamic stability. J. Biol. Chem. 286 (34), 29709-29717.

(35) Blouse, G. E., Perron, M. J., Thompson, J. H., Day, D. E., Link, C. A., and Shore, J. D. (2002) A concerted structural transition in the plasminogen activator inhibitor-1 mechanism of inhibition. Biochemistry 41 (40), 11997-12009.

(36) Magyar, J. S., and Godwin, H. A. (2003) Spectropotentiometric analysis of metal binding to structural zinc-binding sites: accounting 
quantitatively for $\mathrm{pH}$ and metal ion buffering effects. Anal. Biochem. 320 (1), 39-54.

(37) Scheller, K. H., Abel, T. H., Polanyi, P. E., Wenk, P. K., Fischer, B. E., and Sigel, H. (1980) Metal ion/buffer interactions. Stability of binary and ternary complexes containing 2-[bis(2-hydroxyethyl)amino]-2(hydroxymethyl)-1,3-propanediol (Bistris) and adenosine 5'-triphosphate (ATP). Eur. J. Biochem. 107 (2), 455-466.

(38) Anwar, Z. M., and Azab, H. A. (1999) Ternary complexes in solution. Comparison of the coordination tendency of some biologically important zwitterionic buffers toward the binary complexes of some transition metal ions and some amino acids. J. Chem. Eng. Data 44 (6), 1151-1157.

(39) Morgan, C. R., and Engen, J. R. (2009) Investigating solutionphase protein structure and dynamics by hydrogen exchange mass spectrometry. Current Protocols in Protein Science, Chapter 17, Unit 17, 16, pp 17.6.1-17.6.17, Wiley, New York.10.1002/ 0471140864.ps1706s58

(40) Hansen, M., Busse, M. N., and Andreasen, P. A. (2001) Importance of the amino-acid composition of the shutter region of plasminogen activator inhibitor-1 for its transitions to latent and substrate forms. Eur. J. Biochem. 268 (23), 6274-6283.

(41) Schousboe, S. L., Egelund, R., Kirkegaard, T., Preissner, K. T., Rodenburg, K. W., and Andreasen, P. A. (2000) Vitronectin and substitution of a beta-strand $5 \mathrm{~A}$ lysine residue potentiate activityneutralization of PA inhibitor-1 by monoclonal antibodies against alpha-helix F. Thromb. Haemostasis 83 (5), 742-751. 